\title{
Local protein synthesis is a ubiquitous feature of neuronal pre- and postsynaptic compartments.
}

One sentence summary: Protein synthesis occurs in all synaptic compartments, including excitatory and inhibitory axon terminals.

Anne-Sophie Hafner ${ }^{1, *}$, Paul G. Donlin-Asp ${ }^{1,{ }^{*}}$, Beulah Leitch ${ }^{2}$, Etienne Herzog ${ }^{3,4}$, Erin M. Schuman ${ }^{1 \#}$

1: Max Planck Institute for Brain Research, Frankfurt Germany

2: Department of Anatomy, School of Biomedical Sciences and the Brain Health Research Centre, University of Otago, Dunedin, New Zealand

3: Interdisciplinary Institute for Neuroscience, University Bordeaux, UMR 5297, F33000, Bordeaux, France.

4: Interdisciplinary Institute for Neuroscience, CNRS, UMR 5297, F-33000, Bordeaux, France.

${ }^{*}$ Authors contributed equally to this work

\# To whom correspondence should be addressed: erin.schuman@brain.mpg.de 


\begin{abstract}
.
There is ample evidence for localized mRNAs and protein synthesis in neuronal dendrites, however, demonstrations of these processes in presynaptic terminals are limited. We used expansion microscopy to resolve pre- and postsynaptic compartments in brain slices. Most presynaptic terminals in the hippocampus and forebrain contained mRNA and ribosomes. We sorted fluorescently labeled synaptosomes from mouse brain and then sequenced hundreds of mRNA species present within excitatory boutons. After brief metabolic labeling, more them $30 \%$ of all presynaptic terminals exhibited a signal, providing evidence for ongoing protein synthesis. We tested different classic plasticity paradigms and observed unique patterns of rapid pre- and/or postsynaptic translation. Thus presynaptic terminals are translationally competent and local protein synthesis is differentially recruited to drive compartment-specific phenotypes that underlie different forms of plasticity.
\end{abstract}


Neurons are morphologically complex possessing a typical cell body from which emerges elaborately branching dendrites and axons. Indeed, most of a neuron's area is accounted for by its dendrites and axons: for example, the dendrites of rodent pyramidal neuron exceed $10 \mathrm{~mm}$ in length (1) and a human axon (e.g. in the sciatic nerve) can reach up to 1 meter length. The massive network represented by dendrites and axons provides the surface area to accommodate the 1000-10000 synapses, both excitatory and inhibitory, typically formed by an individual neuron. At synapses, the complement of proteins present represents the best phenotypic indicator of both the type and strength of the synapse. The regulation of synaptic proteins, by post-translational modifications and by ongoing protein synthesis and degradation, drives homeostasis and plasticity at synapses (2-4).

It has been proposed that a substantial fraction of proteome supply and remodeling occurs locally within synapses (5-8). While a wealth of data has led to consensus that protein synthesis occurs in mature dendrites $(7,9)$ there has been much less agreement about local translation in mature axons. Many studies have shown that local translation is required for axonal growth during development and repair following injury (e.g. (10-14)). In addition, a few recent studies have shown that mature retinal ganglion cell axons contain competent translational machinery and mRNAs (15) or use presynaptic translation during plasticity at certain synapse types $(16,17)$. In addition, there is ample evidence that invertebrate axons can synthesize proteins (e.g. (18)). Despite these data, controversy has arisen from an inability to detect reliably ribosomes in axons or terminals $(19,20)$ and the persistent idea that axonal protein needs are adequately served by the well-documented system of axonal transport (e.g. (21)).

Here, to determine whether translation in axon terminals is a common feature of mature brains, we used advanced microscopy methods to determine the abundance and diversity of the components required for translation in nerve terminals from multiple mouse brain areas. We also purified a molecularly-defined population of mature presynaptic nerve terminals and directly sequenced the resident mRNA population. Finally, we conducted high-resolution metabolic labeling to ascertain the frequency of protein synthesis events in all synaptic compartments. 


\section{Presynaptic terminals from mouse cortex and hippocampus contain translation machinery}

Efforts to localize molecules or cell biological events to neuronal pre- or postsynaptic compartments using fluorescence microscopy are limited by the tight association of the axonal bouton and the dendritic spine or synapse; the synaptic cleft, the only clear region of separation, is only $\sim 20 \mathrm{~nm}$ wide. Here, in order to increase the resolving power to visualize mRNA molecules in pre- and postsynaptic compartments, we optimized fluorescence in situ hybridization (FISH) and nascent protein detection methods for use with expansion microscopy (22) (Fig. 1A; see Methods). We used adult mouse brain slices or rat cultured hippocampal neurons (DIV 18-21) and found that expansion resulted in an enlargement of both pre- and postsynaptic compartments, with an average expansion of $\sim 3.4$ fold. This yielded a clear separation between the pre- and postsynaptic compartments. To evaluate whether ribosomes and mRNA species are present in defined presynaptic compartments, we used immunolabelling for either excitatory (vGLUT1; $(23,24)$ or inhibitory (VGAT; $(25,26)$ ) nerve terminals in expanded mouse brain sections (both cortex and hippocampus) (Fig. 1B-E) or rat cultured hippocampal neurons. We took care to identify the molecules-of-interest within individual z-sections positively labeled for excitatory or inhibitory terminals. We noted that signal detected outside of immunolabeled compartments corresponded to signal arising from nearby unlabeled cells. We detected ribosomes in a large majority (>75\%) of both excitatory and inhibitory presynaptic nerve terminals, using antibodies directed against either a small (RPS11) or a large (RPL26) ribosomal protein (Fig. 1 B-E). Next, we used FISH probes to detect $18 \mathrm{~s}$ and $28 \mathrm{~s}$ rRNA as well as polyadenylated mRNA (detected with a poly $d(T)$ probe) in expanded samples (Fig. 1B-E). Consistent with the abundance of ribosomal proteins, we detected rRNA in over $80 \%$ of both excitatory and inhibitory nerve terminals (Fig. 1B-E). RNase treatment effectively reduced all rRNA signal. In cultured neurons, we also noted that poly $(A)$ mRNA was abundant, as expected, in dendritic spines. In addition, we used an anti-tau antibody to label axons and detected both $18 \mathrm{~s}$ and $28 \mathrm{~s}$ rRNA in axonal segments. Thus, mRNAs and ribosomes were abundant in excitatory and inhibitory presynaptic nerve terminals from both mouse brain slices and rat hippocampal cultured neurons. 
Isolation and characterization of vGLUT1+ terminals from the adult mouse brain

The presence of poly $(A)$ mRNA in axon terminals suggested the capacity for protein synthesis. However, it did not indicate the breadth of translational machinery or the mRNA population potentially available for translation in identified synapse types. In order to characterize transcripts and translational machinery in excitatory presynaptic terminals, we used our recently developed platform that couples fluorescence-sorting with biochemical fractionation to sort and purify fluorescently labeled synaptosomes (fluorescence-activated synaptosome sorting; FASS) (Fig. 2A). The "pre-sorted" and sorted synaptosomes comprise resealed presynaptic synaptic compartments, sometimes associated with an "open" postsynaptic membrane (27-29) (Fig. 2B); the sorted synaptosomes also lacked dendritic and ER elements. Starting with the forebrain of adult vGLUT1 ${ }^{\text {venus }}$ knock-in mice, in which all vGLUT1 ${ }^{+}$synapses were fluorescently labeled (30), we prepared and sorted vGLUT1 ${ }^{+}$synaptosomes for FISH, immunocytochemistry (Fig. 2C-I) and ultimately RNA sequencing (Fig. 3). We first examined whether the $\mathrm{VGLUT1}^{+}$sorted synaptosome population, reflecting the composition of excitatory synapses in vivo, possessed the molecular elements that we detected in the expanded hippocampal and forebrain tissue (Fig. 1B-C). Using sparse plating of individual $\mathrm{VGLUT}^{+}$synaptosomes combined with imaging we determined the incidence of $\operatorname{poly}(\mathrm{A})$ mRNA and ribosomal proteins together with a postsynaptic density marker protein, PSD-95 (Fig. 2C-I). Over $80 \%$ of all sorted vGLUT1 $^{+}$synaptosomes contained poly(A) mRNA (Fig. 2C,E), ribosomal proteins (Fig. 2D,G,I) and rRNA. As expected, a smaller fraction ( 60\%) of synaptosomes were associated with PSD-95 (Fig. 2C,D,G). To examine whether this is a universal feature of excitatory synapses we also examined ribosomal protein labeling in vGLUT1 ${ }^{+}$synaptosomes sorted from the adult mouse hippocampus or cerebellum. We found a strikingly similar high occupancy of ribosomes in the hippocampal and cerebellar excitatory synapses: $\sim 90 \%$ were positive for ribosome immunolabeling (Fig. 2I). In addition, as observed in adult brain slices, a large majority of the $\mathrm{VGAT}^{+}$immunolabeled synaptosomes were also immunopositive for ribosomes.

We took advantage of the punctate nature of the imaged fluorescent signals to calculate the center-to-center distances for poly(A) mRNA or RPS11 and vGLUT1 or PSD-95 proteins. Using stimulated emission depletion microscopy (STED) we confirmed the tight spatial relationship between vGLUT1 and RPS11. The measured 
distances were consistent with the localization of the presynaptic translation machinery as slightly offset from the synaptic cleft (Fig. $2 \mathrm{H}-\mathrm{I}$ ). This suggests that presynaptic translation occurs away from the active zone. In addition, we optimized expansion microscopy for application to synaptosomes and further probed the spatial organization of the ribosome population relative to the active zone. Synaptosomes were visualized using markers differentially localized within boutons: vGLUT1 (synaptic vesicle pool), bassoon (soluble scaffolding protein) and RIM1 (active zone membrane protein). Consistent with the above data, in the expanded synaptosomes ribosomes (measured with 18s and 28s FISH) were positioned closer to vGLUT1 and Bassoon than the active zone membrane (measured with RIM1 immunolabeling) (Fig. 3A-F). Finally, we used immunoEM to detect the ribosomal protein RPS11 in the pre-sorted synaptosome. We detected RPS11 in a majority of the presynaptic terminals (Fig. 3G-J) and the localization, again offset from the active zone, is consistent with the above data. Thus, the majority of presynaptic terminals, both excitatory and inhibitory, contained both poly(A) mRNA and ribosomal protein, indicating a clear capacity for protein synthesis.

\section{The presynaptic transcriptome of vGLUT1+ terminals}

To discover the transcriptome present in adult mouse presynaptic boutons, we used RNA sequencing to identify the mRNA population of both the pre-sorted and vGLUT1 ${ }^{+}$synaptosomes (see Methods). From 3 biological replicates for each group (pre-sorted and sorted), we obtained in total 244 Mio reads that, following genome alignment, yielded 12,730 transcripts detected in all replicates from both groups (196 Mio uniquely mapped reads in total) (Fig. 4A). We analyzed the transcripts that were significantly enriched or depleted in the vGLUT1 ${ }^{+}$sorted population (relative to the pre-sorted synaptosomes) and identified 468 and 792 transcripts, respectively (Fig. $4 A-B)$. Enriched transcripts overlapped to varying degrees with prior synaptic sequencing studies. Gene ontology analysis of the vGLUT1 ${ }^{+}$enriched transcripts (using the $\sim 12.7 \mathrm{~K}$ transcripts from the input forebrain transcriptome) revealed a significant overrepresentation of genes coding for presynaptic active zone proteins, ribosomal proteins and other groups like synapse (Fig. 4C). Amongst the most enriched in the $\mathrm{vGLUT1}^{+}$presynaptic transcriptome were many well-known presynaptic proteins including Bassoon (Bsn), Rims1-3, Stx6, as well as signaling molecules like Sergef and Rapgef4 (Fig. 4B,F) and mitochondrial proteins. Amongst 
the 792 transcripts depleted in the $v G L U T 1^{+}$transcriptome were many coding for neurotransmitter receptors of the GABA and AMPA family, indicating the depletion of postsynaptic and dendritic components through our synaptosome sorting (Fig. 4D,F). Also, transcripts coding for membrane proteins including endoplasmic reticulum proteins, such as Ergic1, Calr or Sec62, were diminished in the vGLUT1 ${ }^{+}$sorted synaptosomes. There was also a clear depletion of transcripts coding for integral synaptic vesicle proteins (Fig 4D,F), consistent with a recent report of somatic vesicle biogenesis and transport (31). Of note, among the 468 transcripts enriched in vGLUT1 $^{+}$terminals, 62 were known targets of the RNA-binding Fragile $X$ Mental Retardation Protein (FMRP), the loss of which causes fragile $X$ syndrome (Fig. 4E) (32). We validated the presence (or absence) of several of the vGLUT1 ${ }^{+}$enriched transcripts including Rapgef4, Adcy1, Bsn, Kif5a, or Actb in sparsely plated vGLUT1 ${ }^{+}$ synaptosomes using FISH (Fig. 4G,H). Thus presynaptic compartments from adult mouse forebrain contained the requisite machinery and a diverse mRNA population for protein synthesis.

\section{Abundant protein synthesis is detected in presynaptic terminals}

To obtain direct evidence for protein synthesis in synaptic compartments, particularly presynaptic boutons, we adapted the puromycin-based metabolic labeling strategy (33) for detection with electron or expansion microscopy. Cultured hippocampal neurons were briefly labelled with puromycin and then fixed and processed for electron microscopy (EM) using immunogold labeling with an anti-puromycin antibody (see Methods). Using transmission EM, we were able to identify, based on morphological features (see Methods), both dendrites and synapses, including presynaptic boutons, in the images (Fig. 5A). A high fraction of presynaptic boutons and postsynaptic spines contained puromycin-positive gold particles indicating active protein synthesis within the last 10 minutes (Fig. 5A-C). The inclusion of the protein synthesis inhibitor anisomycin or the omission of puromycin, led to a dramatic reduction in the detected gold particles (Fig. 5A-C).

The thin nature of the EM sections precludes a 3D analysis and could result in an under-estimation of ongoing protein synthesis in pre- and postsynaptic compartments. Thus, to address the frequency of translation in a well-resolved 3D volume of both presynaptic boutons and dendritic spines we used metabolic labeling 
in expanded cultured hippocampal neurons (Fig. 5D). Together with 5 min of metabolic labeling of nascent protein synthesis, we conducted immunocytochemical analyses using pre- (vGLUT1 or vGAT, excitatory or inhibitory) and postsynaptic (mCherry volume fill) labeling. By analyzing the coincidence of the synaptic markers with the metabolic label (again, resolved in individual z-sections), we discovered that an average of $\sim 37$ and $61 \%$ of excitatory pre- and postsynaptic compartments, respectively, and $\sim 44 \%$ of inhibitory presynaptic terminals underwent active translation. The protein synthesis signal was dramatically reduced by the addition of the protein synthesis inhibitor anisomycin. Because mitochondria were detected in $\sim 48 \%$ of all presynaptic terminals (34), we asked whether any of the presynaptic metabolic label corresponded to mitochondrial protein synthesis. The positive metabolic label in presynaptic terminals (that overlaps with either vGLUT1 or vGAT compartments) was resistant to chloramphenicol (an inhibitor of prokaryotic/mitochondrial protein synthesis) (Fig. 5F). Consistent with this, immunodetected mitochondria (anti-TOMM20 antibody) did not overlap with either the vGLUT1 or vGAT immunolabelled compartments.

We next validated the local translation of some specific candidate mRNAs, identified in the presynaptic transcriptome (Fig. 4), using Puro-PLA (35) together with immunolabeling to identify postsynaptic and pre-synaptic compartments (anti-Map2 and vGLUT1 antibodies, respectively). With just 5 minutes of metabolic labeling, we visualized, for example, the synthesis of both RapGEF4 and Bassoon in presynaptic compartments (Fig. 5G-H). Thus, excitatory and inhibitory presynaptic boutons (as well as postsynaptic spines) exhibited local translation with a high frequency, in the absence of any exogenous stimulation.

\section{Differential compartment-specific regulation of protein synthesis by plasticity}

Local translation is required for several forms of synaptic plasticity including, but not limited to, potentiation induced by neurotrophins (36), and depression induced by metabotropic glutamate receptor activation $\left(\mathrm{mGluR}_{1 / 5}\right)(37)$ or endocannabinoids (16). Capitalizing on our ability to visualize the protein synthesis that occured in three different synaptic compartments (the dendritic spine and both excitatory and inhibitory presynaptic boutons), we examined the translational signature of these three different forms of plasticity. We treated cultured hippocampal or cortical 
neurons with brain-derived neurotrophic factor (BDNF), an mGluR $\mathrm{R}_{1 / 5}$ agonist ((S)-3,5Dihydroxyphenylglycine hydrate; DHPG) or an endocannabinoid CB1 receptor agonist (arachidonyl-2-chloroethylamide; ACEA), adding a metabolic label for the last 5 minutes of each treatment (Fig. 6A). Immunocytochemical detection of nascent protein and markers of each synaptic compartment was conducted and the samples were then subjected to expansion microscopy. The pattern of protein synthesis in the three compartments of interest, in both brain areas, indicated that each type of plasticity yielded a unique constellation of synaptic translation loci: BDNF caused an increase in local translation in dendritic spines and both excitatory and inhibitory boutons (Fig. 6B-E), DHPG caused an increase in dendritic spines only, and ACEA caused an increase in inhibitory boutons exclusively (Fig. 6C-E). The addition of anisomycin significantly reduced the signal in all conditions. This pattern, while clearly evident in the synaptic compartments, was not observed in either the soma or the total dendrite, strongly suggesting a synaptic, localized response. In separate experiments, we examined whether the above three agonists changed the distribution or amount of poly(A) mRNA and found no significant change. Thus the compartment-specific translation observed above was mediated by local, enhanced translation of mRNAs already resident at the synapse. Furthermore, our results provide subcellular resolution on the local proteomic remodeling that drives different forms of synaptic plasticity.

\section{Discussion}

Here, we investigated the localization and stimulation of protein synthesis in mature synapses and unambiguously identified protein synthesis machinery and translation in individual presynaptic compartments from 3 different brain areas. In adult rodent brain slices and cultured hippocampal neurons we found that over $75 \%$ of both excitatory and inhibitory presynaptic terminals (see also (16) contained rRNA, ribosomes and poly $(A)$ mRNA. Both light (confocal and super-resolution) and electron microscopy revealed in the absence of overt stimulation a surprisingly high level of ongoing protein synthesis in both pre- and postsynaptic compartments: with only 5 min of labeling $\sim 40 \%$ of both excitatory and inhibitory presynaptic terminals and $\sim 60 \%$ of dendritic spines exhibited active translation. Puromycin, a tRNA mimic, was used to metabolically label nascent proteins (33); we used an optimized low 
concentration in order to label nascent peptides while avoiding a complete block of protein synthesis. The stringency of our presynaptic translation measurements (e.g. the requirement that the metabolic label spatially overlap with a vesicular marker immunolabeling) may also lead to an underestimate of actively translating compartments, particularly when compared to the spine measurements where a volume-filling label was used. As such, we believe that the above values likely represent a conservative estimate of the fraction of compartments undergoing translation in the labeling window. Indeed, we could increase the number of active compartments using chemical stimulations. This confirms that we have identified a "lower-bound": we detected an even higher fraction of actively translating compartments ( 81, 54 and 48 percent of spines, vGAT and vGLUT1 terminals) after 5 min of metabolic labeling.

Thousands of mRNA transcripts are present distally in neuronal processes, where they can be locally used for protein synthesis (38-41). Notably, the transcriptome of retinal ganglion cell axons has been characterized both during development $(42,43)$ and the retinal ganglion cell translatome has been identified in the adult mouse (15). Here, using mature mouse forebrain synaptosomes that are enriched for vGLUT1 ${ }^{+}$ presynaptic terminals we identified $\sim 450$ transcripts that were enriched, relative to the "pre-sorted"/bulk synaptosome transcriptome. There were also many transcripts shared between the pre-sorted and sorted synaptosomes that were not enrichment in the vGLUT1 ${ }^{+}$transcriptome but likely represent important translation targets within post- and/or pre-synaptic compartments. Within this $\mathrm{VGLUT1}^{+}$-enriched transcriptome, we detected many mRNAs that code for proteins that regulate vesicle release probability including Rims, Adcy1, and Bsn. Using Puro-PLA (35) we validated the synthesis of several presynaptic proteins, including RapGEF4 and Bassoon, in identified nerve terminals within minutes of metabolic labeling. Some of the earliest studies suggesting translation in axons observed radioactive labeling in synaptosomes $(44,45)$. Interestingly, mRNAs coding for synaptic vesicle proteins were lacking in our vGLUT1 ${ }^{+}$transcriptome. Perhaps local translation of presynaptic proteins could work in concert with the well-documented transport of presynaptic proteins and complexes within axons (46) to supply and regulate neurotransmitter release and homeostasis in mature, healthy nerve terminals. 
We detected an enrichment of transcripts in several functional categories. For example, we noted an abundance of mRNAs coding for proteins that directly regulate translation, including eukaryotic initiation and elongation factors (see also (15)). While many of these proteins have been detected within dendrites $(47,48)$ whether they are present in excess or limited quantities is unknown. Signaling events at the synapse could thus boost translational capacity by synthesizing these potentially rate-limiting regulatory elements. Importantly, local protein synthesis is dysregulated in many neurodevelopmental disorders (49) and recent attention has focused on a presynaptic locus of some important proteins like FMRP (50). In this regard, we note that over $10 \%$ of the vGLUT1 $1^{+}$-enriched presynaptic transcripts possess an FMRPbinding site (32). Shigeoka et al., also observed an abundance of FMRP targets in the retinal ganglion cell axonal translatome (15).

Multiple forms of synaptic plasticity involve local translation in dendrites including, BDNF-induced synaptic potentiation (36), mGluR-dependent long-term depression (51), dopamine-induced plasticity (52) and homeostatic plasticity (48) and activation of presynaptic CB1 receptors by retrograde endocannabinoid signaling stimulates local protein synthesis in inhibitory terminals to produce long-term depression of inhibitory transmission (16). We found local translation in both the pre- and postsynaptic compartments to be differentially regulated by 3 of the above forms of plasticity in a compartment-specific manner. These data indicate that there is also information about the recent synaptic history and the expression of plasticity in the particular pattern of translation loci in synaptic compartments. Together with the selection of particular mRNAs for translation, owing to unique regulatory elements present in the 3'UTRs (53), a unique and remodeled synaptic proteome for each kind of plasticity can be achieved. Our findings demonstrate that local protein synthesis is a ubiquitous feature of both sides of the synapse- it occurs in both excitatory and inhibitory presynaptic boutons, as well as dendritic spines, under basal conditions and is differentially recruited in these compartments to modify local proteomes. Taken together with the well-documented system of microtubule-based transport (in both axons and dendrites) to supply both mRNA and protein, local synthesis adds an 
bioRxiv preprint doi: https://doi.org/10.1101/363184; this version posted March 26, 2019. The copyright holder for this preprint (which was not certified by peer review) is the author/funder. All rights reserved. No reuse allowed without permission.

important source of protein that presumably can be exploited to alter the local proteome with spatial and temporal precision. 


\section{Materials and Methods}

Cultured neurons. Dissociated rat hippocampal or cortical neuron cultures were prepared and maintained as described previously (54). Briefly, we dissected hippocampi or cortices from postnatal day 0-1 rat pups of either sex (SpragueDawley strain; Charles River Laboratories), dissociated them with papain (Sigma) and plated them at a density of $40 \times 10^{3}$ cells $/ \mathrm{cm}^{2}$ on poly-D-lysine coated glassbottom Petri dishes (MatTek). Neurons were maintained and matured in a humidified atmosphere at $37^{\circ} \mathrm{C}$ and $5 \% \mathrm{CO}_{2}$ in growth medium (Neurobasal-A supplemented with B27 and GlutaMAX-I, life technologies) for 18-21 days in vitro (DIV) to ensure synapse maturation. All experiments complied with national animal care guidelines and the guidelines issued by the Max Planck Society, and were approved by local authorities. For transfection, DIV7-11 neurons were transfected with mCherry-C1 or EGFP-C1 using Effectene (Qiagen), as previously described (55). Transfected cells were maintained until DIV18-21 for experiments.

Preparation of mouse brain sections. 12-week-old mice were perfused with $1 \mathrm{x}$ phosphate buffered saline (PBS) and 4\% (v/v) paraformaldehyde solution in PBS. Brains were dissected, and sliced to $2 \mathrm{~mm}$ and fixed for $3 \mathrm{~h}$ at room temperature. Slices were cryoprotected in $20 \%$ (w/v) sucrose in PBS (DEPC-treated) overnight at $4^{\circ} \mathrm{C}$ and cryosectioned at $20 \mu \mathrm{m}$ thickness. Samples were then stored at $-20^{\circ} \mathrm{C}$ in $80 \%$ ethanol until use.

In situ hybridization in synaptosomes and cultured neurons. All steps were performed at room temperature, unless stated otherwise. Bottom glass dishes with attached neurons (DIV 21+) or pre-sorted or vGLUT1+ sorted synaptosomes plated on gelatinized coverslips were fixed in paraformaldehyde $4 \%$ in lysine phosphate buffer pH7.4 containing $2.5 \%$ sucrose for $15-20 \mathrm{~min}$. Target specific in situ hybridization was performed using Stellaris ${ }^{\mathrm{TM}}$ probes (LGC Bioresearch) as previously described (56) and oligo(dT) and $d(A)$ performed as in (57). Following fixation, cells were washed in PBS $+5 \mathrm{mM} \mathrm{MgCl}_{2}$, followed by dehydration in $80 \%$ ethanol overnight at $-20^{\circ} \mathrm{C}$. Samples were rehydrated in $\mathrm{PBS}+\mathrm{MgCl}_{2}$, followed by 2x $1 \mathrm{X}$ saline-sodium citrate (SSC) washes, followed by a 5 min wash in $2 \mathrm{X}$ SSC + 
$30 \%$ formamide for $5 \mathrm{~min}$. Biotin labeled probes for $18 \mathrm{~S}$ and $28 \mathrm{~S}$ rRNA (Stellaris, Biosearch technology), and 18mer oligo(dT)/oligo(dA) (Eurofins) were diluted into $100 \mu \mathrm{l}$ hybridization buffer and incubated on cells overnight at $37^{\circ} \mathrm{C}$. Following probe hybridization, samples were washed twice in 2X SSC $+30 \%$ formamide for 30 minutes each, followed by $5 x 1 X$ SSC washes. After completion of in situ hybridization, samples were washed with PBS and subsequently processed for immunofluorescence. For RNaseA/T1 controls $1 \mathrm{~mL}$ of digestion buffer (10 mM Tris$\mathrm{HCl}, 300 \mathrm{mM} \mathrm{NaCl}, 5 \mathrm{mM}$ EDTA) was added to sample with and without $20 \mathrm{uL}$ of RNaseA/T1 (Thermo Fisher) for $30 \mathrm{~min}$ at $37^{\circ} \mathrm{C}$ following sample rehydration. For permeabilization controls, EtOH dehydration series were omitted.

\section{In situ hybridization in tissue.}

Following rehydration, samples were postfixed for 5 min in ice cold 4\% PFA, followed by washes in 2xSSC. Samples were treated with $0.1 \mathrm{M}$ triethanolamine- $\mathrm{HCl} \mathrm{pH} 8.0+$ acetic anhydride for 10 min to reduce nonspecific hybridization. Following washing in ice cold $\mathrm{H}_{2} \mathrm{O}$ samples were incubated in ice cold methanol/acetone, and then washed in ice cold 1x SSC. Samples were blocked for endogenous biotin using streptavidin for $30 \mathrm{~min}$ at $37^{\circ} \mathrm{C}$ followed by a biotin was for $5 \mathrm{~min}$ (Thermo Fisher). Samples were then incubated in 2X SSC for 10 min, followed by 2X SSC $+50 \%$ Formamide for $1 \mathrm{~h}$. FISH probes were diluted to $2 \mathrm{X}$ in $200 \mu \mathrm{L}$ hybridization buffer and incubated overnight at $37^{\circ} \mathrm{C}$. Samples were washed $5 \mathrm{x}$ in $2 \mathrm{X} \mathrm{SSC}+50 \%$ formamide for 60 min each at $37^{\circ} \mathrm{C}$, followed by 5 washes in $2 \mathrm{X}$ SSC for 10 min each. After completion of in situ hybridization, samples were washed with PBS and subsequently processed for immunofluorescence.

Immunofluorescence in synaptosomes and cultured neurons. All steps were performed at room temperature, unless stated otherwise. Bottom glass dishes with attached neurons (DIV 18-21) or pre-sorted or vGLUT1+ sorted synaptosomes plated on gelatinize coverslips were fixed in paraformaldehyde $4 \%$ in lysine phosphate buffer pH7.4 containing $2.5 \%$ of sucrose for $15-20 \mathrm{~min}$. Cells were then permeabilized for $10 \mathrm{~min}$ in PBS $+0.5 \%$ Triton-X 100 (Sigma). Samples were incubated in blocking buffer (4\% goat serum in PBS) or biotin-free blocking buffer (4\% biotin free BSA in PBS, for FISH experiments) for 30 min. After 3 washes in PBS 
for 5 min each, samples were incubated in blocking buffer (4\% goat serum in PBS for cell culture experiments, $4 \%$ biotin free BSA in PBS for cell culture FISH experiments) for 1 to $2 \mathrm{~h}$ with secondary antibodies. We used the following antibodies: guinea pig anti-MAP2 (Synaptic Systems, 1:2000), rabbit anti-biotin (Bethyl, 1:1000), rabbit anti-biotin (Cell Signaling, 1:1000), chicken anti-GFP (Aves, 1:1000), chicken anti-mCherry (Abcam, 1:1000), mouse anti-PSD-95 (Thermo Fisher Scientifics, 1:1000), mouse anti-synaptopodin (Merck, 1:500), rabbit anti-calreticulin (Abcam, 1:1000), guinea pig anti-Homer1 (Synaptic Systems, 1:1000), mouse antiPuromycin (Kerafast, 1:500-1000), guinea pig anti-VGLUT1 (Synaptic Systems, 1:500-2000), guinea pig anti-VGAT (Synaptic Systems, 1:500-2000), rabbit antiVGAT (Synaptic Systems, 1:1000), mouse anti-Smi-312 (Covance, 1:2000), rabbit anti-RPS11 (Bethyl, 1:200), rabbit anti-RPL26 (Sigma, 1:500-1000). After 3 washes in PBS for 5 min each, samples were incubated in blocking buffer (4\% goat serum in PBS) for 1 to $3 \mathrm{~h}$ at room temperature with secondary antibodies. For expansion microscopy, we used the following dyes coupled to our secondary antibodies: Alexa488, Alexa-568, Abberior STAR-635.

Immunofluorescence in tissue sections. Brain sections were incubated in $4 \%$ goat serum $+0.5 \%$ Triton-X 100 for normal IF or $4 \%$ biotin free BSA $+0.5 \%$ Triton-X 100 for FISH experiments at room temperature for $4 \mathrm{~h}$. Primary antibody staining was carried out overnight in the same buffer at $4^{\circ} \mathrm{C}$. Samples were washed $5 x$ in PBS before carrying out secondary antibody staining for $3 \mathrm{~h}$ at room temperature.

Total protein labeling. Prior to permeabilization cells or tissue were incubated with $0.2 \mathrm{M}$ bicarbonate buffer supplemented with $0.5 \mathrm{mg} / \mathrm{mL}$ Alexa568 NHS Ester (Thermo) for $15 \mathrm{~min}$ at room temperature, to label all amine groups in the sample with the Alexa dye. Samples were washed 5x with PBS and used for subsequent IF or FISH experiments.

Cell treatments. For puromycin labeling experiments, cultured neurons were treated with $10 \mu \mathrm{M}$ puromycin for $5 \mathrm{~min}$, if not stated otherwise. Anisomycin treatment (40 $\mu \mathrm{M})$ was performed 20-45 min prior to puromycin labeling. BDNF (50 ng/mL) was added for $10 \mathrm{~min}$, arachidonyl-2-chloroethylamide (ACEA; $50 \mu \mathrm{M}$ ) was added for 10 
min and (S)-3,5-Dihydroxyphenylglycine hydrate (DHPG; $50 \mu \mathrm{M}$ ) was added for 5 min. For mitochondrial protein synthesis inhibition experiments, $40 \mu \mathrm{M}$ chloramphenicol was added for 40 min prior to the addition of puromycin.

Expansion microscopy. Following immunofluorescence labelling, samples were treated with Acryloyl-X-SE (Thermo Fisher) overnight at room temperature. Following washing steps, $200 \mu \mathrm{l}$ of monomer solution was added to the coverslip and gelation was carried out at $37^{\circ} \mathrm{C}$ for $1 \mathrm{~h}$. For tissue sections, water was replaced with 4hydroxy TEMPO (Thermo Fisher) as previously described (22). Tissue sections were pre-incubated in monomer solution at $4^{\circ} \mathrm{C}$ for $30 \mathrm{~min}$, prior to transferring the samples to $37^{\circ} \mathrm{C}$ for $2 \mathrm{~h}$ to allow gelation to occur. Following ProteinaseK (NEB) digestion overnight, slightly expanded gels were transferred to a larger dish and water exchange was performed until gels were fully expanded. Expanded gels were transferred into 50x7 mm glass bottom dishes (WillCo Wells) for imaging. Expanded gels were imaged using Zeiss LSM780/880 confocal microscopes and a 63x oil

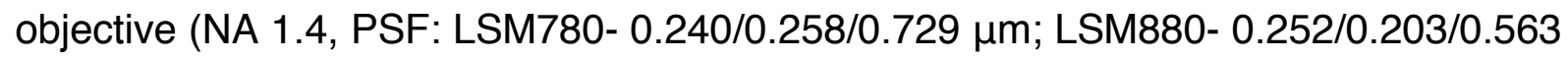
$\mu \mathrm{m} x / y / z)$ for cultured cells and synaptosomes and a $40 x$ oil objective (NA 1.3, PSF: LSM780- 0.217/0.260/0.566 $\mu \mathrm{m}$; LSM880- 0.238/0.253/0.636 $\mu \mathrm{m} \quad \mathrm{x} / \mathrm{y} / \mathrm{z}$ ). Zstacks $(0.37 \mu \mathrm{m} 63 \mathrm{x} / 0.43 \mu \mathrm{m} \mathrm{40x})$ spanning the entire volume of imaged neurons, synaptosomes or tissue were obtained and analyzed using Imaris (Bitplane) and ImageJ.

Image analysis. To assess signal occupancy in spines or boutons, the compartment was considered positive for either puromycin or RNA if signal was detected in at least 3 individual consecutive $z$ slices. Presynaptic terminals were defined by vGLUT1 and VGAT signal, and spines were defined based on morphology from mCherry or GFP volume filling. To be considered a spine, the compartment must be a clearly defined protrusion from the dendrite- extending at least 1.5um away (in the expanded images) from the dendritic shaft. For tissue sections, due to the increased density and complexity of the samples, images were first processed in Imaris. 3D surface masks were generated corresponding to either vGLUT1 or vGAT signal. These presynaptic surface masks were used to generate a new channel, corresponding to the puromycin or RNA signal found within the 3D presynaptic volume. These images 
were then compressed into max intensity projections, and the number of positive VGLUT or VGAT terminals were scored, positive or negative, based on the presynaptic puromycin or RNA channel. To assess the amount of signal falling within and outside of cells, samples with total protein labeled (Alexa-568 NHS ester- see total protein labeling section) and FISH were analyzed in Imaris. The total protein Alexa-568 channel was used to make a 3D surface mask, and all RNA FISH signal falling within this mask was copied into a new third channel. The total signal intensity of the original RNA FISH signal channel was then measured as well as the signal corresponding to the FISH signal within cells. The ratio of cellular signal/total signal was used to assess the fraction of signal falling within cells. For soma and dendrite relative puromycin incorporation measurements, sum intensity projections were made and using the mCherry signal as a mask. The soma or the dendrite (starting $15 \mu \mathrm{m}$ away from the cell body, and extending for at least $70 \mu \mathrm{m}$ ) was selected and total puro signal was assessed and normalized to the dendritic or soma area.

Proximity ligation assay (PLA). Detection of newly synthesized proteins by proximity ligation was carried out using anti-puromycin antibodies (mouse antiPuromycin from Kerafast, 1:500-1000) in combination with protein-specific antibodies (rabbit anti-RapGEF4 from Invitrogen, 1:250; rabbit anti-bassoon from Enzo, 1:500; rabbit anti-beta-actin from Abcam, 1:1000). We used Duolink reagents (Sigma) and followed the protocol provide by the manufacturer with some modifications described below. We routinely used rabbit PLA ${ }^{\text {plus }}$ and mouse PLA ${ }^{\text {minus }}$ probes as secondary antibodies and the "Duolink Detection reagents Red" (Sigma) for ligation, amplification and label probe binding. Briefly, after a brief $5 \mathrm{~min}$ of metabolic labeling, hippocampal cultured neurons (21 DIV) were fixed in PBSsucrose, permeabilized in PBS + 0.5\% Triton-X 100 and blocked in PBS + 4\% goat serum as described previously for immunocytochemistry assays. Then, neurons were incubated overnight at $4^{\circ} \mathrm{C}$ in PBS $+4 \%$ goat serum containing primary antibodies: mouse anti-puromycin, rabbit anti-protein of interest (e.i. antiRapGEF4, Bassoon or beta-actin), chicken anti-MAP2 (Abcam, 1:2000) and guinea-pig anti-vGLUT1 (Synaptic System, 1:1000). After washing, PLA probes were applied in 1:10 dilution in PBS with $4 \%$ goat serum for $1 \mathrm{~h}$ at $37^{\circ} \mathrm{C}$, washed several times with wash buffer $\mathrm{A}(0.01 \mathrm{M}$ Tris, $0.15 \mathrm{M} \mathrm{NaCl}, 0.05 \%$ Tween 20$)$ and 
incubated for $30 \mathrm{~min}$ with the ligation reaction containing the circularization oligos and T4 ligase prepared according to the manufacturer's recommendations (Duolink Detection reagents Red, Sigma) in a prewarmed humidified chamber at $37^{\circ} \mathrm{C}$. Amplification and label probe binding was performed after further washes with wash buffer A with the amplification reaction mixture containing Phi29 polymerase and the fluorophore-labeled detection oligo prepared according to the manufacturer's recommendations (Duolink Detection reagents Red, Sigma) in a prewarmed humidified chamber at $37^{\circ} \mathrm{C}$ for $100 \mathrm{~min}$. Amplification was stopped by three washes in wash buffer $\mathrm{B}(0.2 \mathrm{M}$ Tris, $0.1 \mathrm{M} \mathrm{NaCl}, \mathrm{pH}$ 7.5). We note that for better signal stability, cells were kept in wash buffer $\mathrm{B}$ at $4^{\circ} \mathrm{C}$ until imaging.

\section{Pre-embedding immuno-detection of newly synthesized proteins visualized by} electron microscopy. For the detection of newly synthetized proteins in neurons, we performed pre-embedding immuno-detection of puromycin as described below. All steps were performed at room temperature, if not stated otherwise. Bottom glass dishes with attached neurons (DIV 28) were fixed in paraformaldehyde $4 \%$ and $0.05 \%$ glutaraldehyde in $0.2 \mathrm{mM}$ HEPES buffer $\mathrm{pH} 7.2$ for $45 \mathrm{~min}$. Cells were then permeabilized for $10 \mathrm{~min}$ in PBS containing 0.5\% Triton-X 100 (Sigma). Fixation reagents were quenched using freshly made $1 \mathrm{mg} / \mathrm{ml}$ borohydride in HEPES $0.2 \mathrm{mM}$ pH8 for $10 \mathrm{~min}$. Antibodies were applied on the samples in blocking buffer (PBS + $2 \%$ biotin-free BSA). After $30 \mathrm{~min}$ in blocking buffer cells were incubated with mouse anti-puromycin (Kerafast, 1:2000) for $1 \mathrm{~h}$ at room temperature. Prior to the $1 \mathrm{~h}$ incubation at room temperature with anti-mouse antibody coupled to biotin (Abcam, 1:1000) we performed an endogenous biotin-block (Thermo Fisher). Biotin was detected with a rabbit anti-biotin antibody coupled to $1 \mathrm{~nm}$ nanogold particles $(1: 100$, FluoroNanogold Alexa-594, Nanoprobes). Samples were post-fixed in $1 \%$ glutaraldehyde in $0.2 \mathrm{mM}$ HEPES $\mathrm{pH}=7.2$ for $30 \mathrm{~min}$ and fixation was quenched with $100 \mathrm{mM}$ Glycine in PBS for $10 \mathrm{~min}$. Samples were then washed in water three times and then three times with $20 \mathrm{mM}$ sodium citrate buffer $\mathrm{pH}=7.0$. Nanogold particles were subsequently amplified using silver amplification for $6 \min$ (Serva) and fixed again in $0.2 \%$ OsO4 for 30 min. Samples were then stained with $0.25 \%$ uranyl acetate (Serva) in the dark for $30 \mathrm{~min}$. After washing and dehydrating with ethanol, samples were embedded in Epon (Serva). Sections (60 nm thick) were mounted onto 
Formvar-coated copper grids (Serva). Grids were imaged with a transmission electron microscope LEO (Zeiss) 912 OMEGA.

Synaptosome isolation. Synaptosomes were generated from 6-8 weeks old mouse

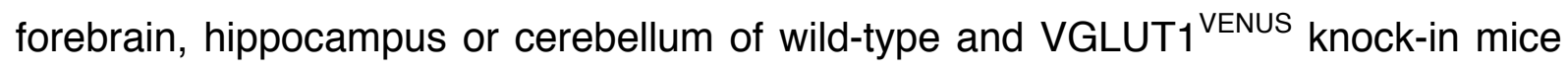
as described previously $(27,28,30)$. Our synaptosome preparation was chosen and adapted from our previously published protocol (27-29) to favor the isolation of synaptosomes with presynaptic compartments with closed membrane bilayers and postsynaptic compartments with open membrane bilayers. Briefly, the cerebellum, forebrain, or both hippocampi from a single mouse was homogenized in $2 \mathrm{~mL}$ of icecold homogenization buffer (0.32 M sucrose, $4 \mathrm{mM}$ HEPES pH 7.4, protease inhibitor cocktail EGTA-free (Calbiochem, 1:1000), RNasin (Promega, 1:1000) using a $2 \mathrm{~mL}$ glass-Teflon homogenizer with 12 gentle strokes. The homogenizer was then rinsed with additional $3 \mathrm{~mL}$ of homogenization buffer, and the combined $5 \mathrm{~mL}$ of homogenate was centrifuged at $1000 \mathrm{~g}$ for $8 \mathrm{~min}$ at $4^{\circ} \mathrm{C}$. The supernatant was centrifuged again at $12,500 \mathrm{~g}$ for $15 \mathrm{~min}$ at $4^{\circ} \mathrm{C}$. The synaptosome-enriched pellet was then re-suspended in $1 \mathrm{~mL}$ of homogenization buffer. This fraction was finally layered on top of a two-step sucrose density gradient $(5 \mathrm{~mL}$ of $1.2 \mathrm{M}$ and $5 \mathrm{~mL}$ of 0.8 M sucrose, HEPES $4 \mathrm{mM}$, protease inhibitor cocktail EGTA-free, as above). The gradient was centrifuged at $50,000 \mathrm{~g}$ for $70 \mathrm{~min}$ at $4^{\circ} \mathrm{C}$. Synaptosomes were recovered through the tube wall, at the interface of 0.8 and $1.2 \mathrm{M}$ sucrose, using a syringe to minimize contamination with lighter fractions enriched in myelin. The resulting fraction is referred as pre-sorted (sucrose) synaptosomes (or Ssynaptosomes) as opposed to $\mathrm{VGLUT1}^{+}$sorted synaptosomes (or FASSsynaptosomes).

\section{Post-embedding immuno-detection of ribosomal protein RPS11 visualized by} electron microscopy. Pre-sorted synaptosomes $(\sim 750 \mu \mathrm{l})$ on iced were mixed with ice cold PBS containing protease inhibitor cocktail EGTA-free (Calbiochem, 1:1000) and RNasin (Promega, 1:1000) to obtain a final volume of $1.5 \mathrm{ml}$. Pre-sorted synaptomes were centrifuged at $16.8 \mathrm{~g}$ for $5 \mathrm{~min}$ at $4^{\circ} \mathrm{C}$. All the subsequent steps were performed at room temperature unless stated otherwise. The resulting pellet was then fixed using in PBS $+4 \%$ PFA $+2 \%$ glutaraldehyde for $1 \mathrm{~h}$. The pellet was 
then cut in 2 to 4 pieces, that were then washed 4x in PBS and $5 x$ in $\mathrm{H}_{2} \mathrm{O}$ before post-fixation in $0.2 \%$ OsO4 in water for $30 \mathrm{~min}$. Samples were then stained with $0.25 \%$ uranyl acetate (Serva) in the dark for $30 \mathrm{~min}$. After washing and dehydrating with ethanol, samples were embedded in Epon (Serva). Sections (60 nm thick) were mounted onto nickel grids (Serva) and processed for immunostaining. After 3 washes in TBST, grids were blocked for $10 \mathrm{~min}$ in TBST with 10\% Normal Goat Serum (NGS). Antibodies were applied in TBST with 1\% NGS. Grids were incubated with anti-RPS11 (Bethyl, 1:200) overnight in the dark. The next day grids were washed 5x 3 min with TBS before being incubated with anti-rabbit antibody coupled to $\sim 10 \mathrm{mn}$ colloidal gold (BBI solution, 1:50) for $2 \mathrm{~h}$. Finally, grids were washed 3x 5min in TBS, $3 \times 5$ min PBS, 3x 5 min in $\mathrm{H}_{2} \mathrm{O}$ and further stained with $0.4 \%$ uranyl acetate (Serva) and contrasted with lead citrate (Merck). Grids were imaged with a transmission electron microscope LEO (Zeiss) 912 OMEGA. Control grids in which the primary antibody against RPS11 was omitted yielded no gold signal in presynaptic terminals.

Fluorescence-activated synaptosomes sorting (FASS). S-synaptosome sorting was performed as described previously $(27,28)$. The FACSAria-II (BD Biosciences) operated using a $70 \mu \mathrm{m}$ nozzle. Briefly, S-synaptosomes were stored on ice and diluted in PBS containing protease and RNAase inhibitor as above and labeled with a red (excitation/emission maxima $\sim 515 / 640 \mathrm{~nm}$ ) lipophilic dye FM4-64 (Thermo Fisher Scientific, $1.5 \mu \mathrm{g} / \mathrm{mL}$ ). Dilution was optimized to obtain an event rate of $20,000-$ 25,000 events/s. FM4-64 was used to trigger the FACSAria detection on all biological membranes in the sample. A first gate delineated small particles (singlets) and excluded events showing correlated high values for FSC and SSC area (aggregates and large particles). The "singlets" gate was sub-gated according to vGLUT1 VENUS fluorescence intensity using the 488 laser line. Thus "singlets" were sorted into two fractions, the vGLUT1 $1^{\mathrm{VENUS}}$ negative fraction (VGLUT1') and the vGLUT1 ${ }^{\mathrm{VENUS}}$ positive fraction $\left(\mathrm{vGLUT1} 1^{+}\right)$. Those two fractions were subsequently either collected onto filters and processed for RNA Next Generation Sequencing (NGS) or plated onto gelatinized coverslips at a density of 1 Mio particles per $12 \mathrm{~mm}$ coverslips by centrifugation at $6,800 \mathrm{~g}$ for $34 \mathrm{~min}$ in 24 well plates and then processed for immunofluorescence and/or in situ hybridization (see protocol above). 
Stimulation Emission Depletion microscopy (STED). Super resolved images of vGLUT1 ${ }^{+}$-sorted synaptosomes were obtained using a Leica SP8 WLL2 inverted DMI6000 confocal microscope (Leica Microsystems, Mannheim, Germany) equipped with the 3D STED module. In the STED module, we used a $775 \mathrm{~nm}$ laser line to deplete Alexa-594 and ATTO-647N. We achieved two color STED with a final 40 $\mathrm{nm}$ resolution using a 93X glycerol objective NA 1.30 and a white light laser 2 (WLL2) with freely tunable excitation from 470 to $670 \mathrm{~nm}$ (1 nm steps) and a diode laser at $405 \mathrm{~nm}$. The microscope was equipped with 2 internal PMTs and 2 internal hybrid detectors.

RNA Next Generation Sequencing. Total RNA were extracted using TRIzol LS reagent (Thermo Fisher) and Direct-zol RNA microprep kit (Zymo) for four different samples: input (mouse forebrain) from wildtype and VGLUT1 ${ }^{\mathrm{VENUS}}$ mice, pre-sorted synaptosomes from wildtype and VGLUT1 $1^{\mathrm{VENUS}}$ mice; and $\mathrm{VGLUT1}^{+}$sorted synaptosomes VGLUT1 ${ }^{\text {VENUS }}$ mice $\mathrm{P} 3$ fractions (after filtration to remove the excess of PBS). Total RNA libraries were generated using NEBNext rRNA Depletion kit combined with NEBNext Ultra II Direction RNA Library Prep kit for Illumina (New England Biolabs). We used $100 \mathrm{ng}$ of starting RNA material for input and pre-sorted synaptosomes and 1-5 ng for vGLUT1 ${ }^{+}$sorted synaptosomes which corresponds to 100 Mio synaptosomes collected per P3 fractions. In the final amplification step of the library preparation or PCR enrichment step we used 12 cycles of amplification for the input and pre-sorted synaptosomes and 16 cycles of amplification for amplification the $\mathrm{vGLUT1}^{+}$sorted synaptosomes. Ultimately we obtained cDNA libraries of $\sim 250 \mathrm{bp}$ with each sample containing a specific barcode. Libraries corresponding to replicates 1 and 2 were sequenced together in the same sequencing run. The libraries corresponding to replicates 3 and 4 (only used as an input sample) were sequenced in a subsequent run. For sequencing we used $10 \mathrm{ng}$ of starting material for each library in a high throughput Illumina flow cell using Illumina NextSeq 550 Instrument.

RNA Sequencing data analysis. For detection and annotation of the sequencing reads we used the following pipeline: 
i) Genome alignment. Reference genome was mouse version mm10 from UCSC (link: http://hgdownload.soe.ucsc.edu/goldenPath/mm10/bigZips/). Reads alignment was conducted with STAR aligner (58) (version 2.5.2) with the following parameters: STAR --runMode alignRead --genomeDir \$path_genome_index_mm10 -readFilesCommand zcat --outStd Log --outSAMtype BAM SortedByCoordinate -outSAMstrandField intronMotif --outFilterIntronMotifs RemoveNoncanonical -alignSoftClipAtReferenceEnds No --outFilterScoreMinOverLread $0.25 \quad$-outFilterMatchNminOverLread 0.25

ii) Annotation assignment. Annotation GTF file was downloaded from UCSC Table Browser Tool with the following parameters:

Clade: Mammal, genome: Mouse, assembly: Dec. 2011 (GRCm38/mm10), group: Genes and Gene Predictions, track: NCBI RefSeq, table: RefSeq All (ncbiRefSeq), output format: GTF - gene transfer format (limited) (link: http://genome.ucsc.edu/cgibin/hgTables?hgsid=706713641_R7J6gGZbwmO18wecxAAiXglgAlzN\&clade=mamm al\&org=Mouse\&db=mm10\&hgta_group=genes\&hgta_track=refSeqComposite\&hgta_t able=0\&hgta_regionType=genome\&position=chr12\%3A56694976-

56714605\&hgta_outputType=primaryTable\&hgta_outFileName=)

Gene expression was counted using featureCounts (link: http://bioinf.wehi.edu.au/featureCounts/) parameters: featureCounts -a

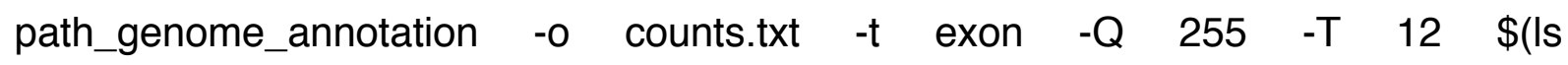
/path/bams/files/*.bam)

iii) Differential Expression analysis. Differential Expression analysis was performed using DESeq2 in $R$ (available at https://bioconductor.org/packages/release/bioc/html/DESeq2.html) setting the differential expression cut-off to 1.3-fold change and false discovery rate $q \leq 0.1$ using the Benjamini-Hochberg method $(59,60)$.

iv) Detection of poly $(A / T)$ repeats. A fuzzy polyA match algorithm was adapted from Kent WJ, GenomeRes. 2002 (https://www.ncbi.nlm.nih.gov/pubmed/11932250), Iterator will start at every position on the sequence with two consecutive Adenine (A) (or thymine $(\mathrm{T})$ respectively), setting initial score to 10 . Every match adds a score of 1 and a mismatch adds a score of -8 . The iterator will stop incrementing when the score value drops below 0 . The longest span of the iterator is kept per transcript as a measure of detected repeat sequence. 
bioRxiv preprint doi: https://doi.org/10.1101/363184; this version posted March 26, 2019. The copyright holder for this preprint (which was not certified by peer review) is the author/funder. All rights reserved. No reuse allowed without permission.

All Venn diagrams were obtained using Venn 2.1 web tools (61). 


\section{References and Notes.}

1. N. J. Bannister, A. U. Larkman, Dendritic morphology of CA1 pyramidal neurones from the rat hippocampus: II. Spine distributions. J Comp Neurol 360, 161-171 (1995).

2. A. R. Dorrbaum, L. Kochen, J. D. Langer, E. M. Schuman, Local and global influences on protein turnover in neurons and glia. Elife 7, (2018).

3. C. T. Schanzenbacher, S. Sambandan, J. D. Langer, E. M. Schuman, Nascent Proteome Remodeling following Homeostatic Scaling at Hippocampal Synapses. Neuron 92, 358-371 (2016).

4. C. Hanus, E. M. Schuman, Proteostasis in complex dendrites. Nat Rev Neurosci 14, 638-648 (2013).

5. K. C. Martin, A. Ephrussi, mRNA localization: gene expression in the spatial dimension. Cell 136, 719-730 (2009).

6. S. J. Van Driesche, K. C. Martin, New frontiers in RNA transport and local translation in neurons. Dev Neurobiol 78, 331-339 (2018).

7. C. Glock, M. Heumuller, E. M. Schuman, mRNA transport \& local translation in neurons. Curr Opin Neurobiol 45, 169-177 (2017).

8. M. Crispino, J. T. Chun, C. Cefaliello, C. Perrone Capano, A. Giuditta, Local gene expression in nerve endings. Dev Neurobiol 74, 279-291 (2014).

9. C. E. Holt, E. M. Schuman, The central dogma decentralized: new perspectives on RNA function and local translation in neurons. Neuron $\mathbf{8 0}$, 648-657 (2013).

10. D. S. Campbell, C. E. Holt, Chemotropic responses of retinal growth cones mediated by rapid local protein synthesis and degradation. Neuron 32, 10131026 (2001).

11. C. J. Donnelly, M. Fainzilber, J. L. Twiss, Subcellular communication through RNA transport and localized protein synthesis. Traffic 11, 1498-1505 (2010).

12. K. M. Leung, F. P. van Horck, A. C. Lin, R. Allison, N. Standart, C. E. Holt, Asymmetrical beta-actin mRNA translation in growth cones mediates attractive turning to netrin-1. Nat Neurosci 9, 1247-1256 (2006).

13. D. E. Willis, E. A. van Niekerk, Y. Sasaki, M. Mesngon, T. T. Merianda, G. G. Williams, M. Kendall, D. S. Smith, G. J. Bassell, J. L. Twiss, Extracellular stimuli specifically regulate localized levels of individual neuronal mRNAs. $J$ Cell Biol 178, 965-980 (2007).

14. A. Poulopoulos, A. J. Murphy, A. Ozkan, P. Davis, J. Hatch, R. Kirchner, J. D. Macklis, Subcellular transcriptomes and proteomes of developing axon projections in the cerebral cortex. Nature, (2019).

15. T. Shigeoka, H. Jung, J. Jung, B. Turner-Bridger, J. Ohk, J. Q. Lin, P. S. Amieux, C. E. Holt, Dynamic Axonal Translation in Developing and Mature Visual Circuits. Cell 166, 181-192 (2016).

16. T. J. Younts, H. R. Monday, B. Dudok, M. E. Klein, B. A. Jordan, I. Katona, P. E. Castillo, Presynaptic Protein Synthesis Is Required for Long-Term Plasticity of GABA Release. Neuron 92, 479-492 (2016).

17. M. S. Scarnati, R. Kataria, M. Biswas, K. G. Paradiso, Active presynaptic ribosomes in the mammalian brain, and altered transmitter release after protein synthesis inhibition. Elife 7, (2018).

18. A. Giuditta, W. D. Dettbarn, M. Brzin, Protein synthesis in the isolated giant axon of the squid. Proc Natl Acad Sci U S A 59, 1284-1287 (1968). 
19. R. J. Lasek, C. Dabrowski, R. Nordlander, Analysis of axoplasmic RNA from invertebrate giant axons. Nat New Biol 244, 162-165 (1973).

20. M. R. Akins, H. E. Berk-Rauch, J. R. Fallon, Presynaptic translation: stepping out of the postsynaptic shadow. Front Neural Circuits 3, 17 (2009).

21. R. D. Vale, T. S. Reese, M. P. Sheetz, Identification of a novel forcegenerating protein, kinesin, involved in microtubule-based motility. Cell 42, 3950 (1985).

22. P. W. Tillberg, F. Chen, K. D. Piatkevich, Y. Zhao, C. C. Yu, B. P. English, L. Gao, A. Martorell, H. J. Suk, F. Yoshida, E. M. DeGennaro, D. H. Roossien, G. Gong, U. Seneviratne, S. R. Tannenbaum, R. Desimone, D. Cai, E. S. Boyden, Protein-retention expansion microscopy of cells and tissues labeled using standard fluorescent proteins and antibodies. Nat Biotechnol 34, 987992 (2016).

23. E. Herzog, G. C. Bellenchi, C. Gras, V. Bernard, P. Ravassard, C. Bedet, B. Gasnier, B. Giros, S. El Mestikawy, The existence of a second vesicular glutamate transporter specifies subpopulations of glutamatergic neurons. $J$ Neurosci 21, RC181 (2001).

24. R. T. Fremeau, Jr., M. D. Troyer, I. Pahner, G. O. Nygaard, C. H. Tran, R. J. Reimer, E. E. Bellocchio, D. Fortin, J. Storm-Mathisen, R. H. Edwards, The expression of vesicular glutamate transporters defines two classes of excitatory synapse. Neuron 31, 247-260 (2001).

25. S. L. Mclntire, R. J. Reimer, K. Schuske, R. H. Edwards, E. M. Jorgensen, Identification and characterization of the vesicular GABA transporter. Nature 389, 870-876 (1997).

26. C. Sagne, S. El Mestikawy, M. F. Isambert, M. Hamon, J. P. Henry, B. Giros, B. Gasnier, Cloning of a functional vesicular GABA and glycine transporter by screening of genome databases. Febs Lett 417, 177-183 (1997).

27. E. Luquet, C. Biesemann, A. Munier, E. Herzog, Purification of Synaptosome Populations Using Fluorescence-Activated Synaptosome Sorting. Methods Mol Biol 1538, 121-134 (2017).

28. C. Biesemann, M. Gronborg, E. Luquet, S. P. Wichert, V. Bernard, S. R. Bungers, B. Cooper, F. Varoqueaux, L. Li, J. A. Byrne, H. Urlaub, O. Jahn, N. Brose, E. Herzog, Proteomic screening of glutamatergic mouse brain synaptosomes isolated by fluorescence activated sorting. EMBO $\mathrm{J} 33,157-$ 170 (2014).

29. V. P. Whittaker, I. A. Michaelson, R. J. Kirkland, The separation of synaptic vesicles from nerve-ending particles ('synaptosomes'). Biochem J 90, 293-303 (1964).

30. E. Herzog, F. Nadrigny, K. Silm, C. Biesemann, I. Helling, T. Bersot, H. Steffens, R. Schwartzmann, U. V. Nagerl, S. El Mestikawy, J. Rhee, F. Kirchhoff, N. Brose, In vivo imaging of intersynaptic vesicle exchange using VGLUT1 Venus knock-in mice. J Neurosci 31, 15544-15559 (2011).

31. A. Vukoja, U. Rey, A. G. Petzoldt, C. Ott, D. Vollweiter, C. Quentin, D. Puchkov, E. Reynolds, M. Lehmann, S. Hohensee, S. Rosa, R. Lipowsky, S. J. Sigrist, V. Haucke, Presynaptic Biogenesis Requires Axonal Transport of Lysosome-Related Vesicles. Neuron 99, 1216-1232 e1217 (2018).

32. J. C. Darnell, S. J. Van Driesche, C. Zhang, K. Y. Hung, A. Mele, C. E. Fraser, E. F. Stone, C. Chen, J. J. Fak, S. W. Chi, D. D. Licatalosi, J. D. Richter, R. B. 
Darnell, FMRP stalls ribosomal translocation on mRNAs linked to synaptic function and autism. Cell 146, 247-261 (2011).

33. E. K. Schmidt, G. Clavarino, M. Ceppi, P. Pierre, SUnSET, a nonradioactive method to monitor protein synthesis. Nat Methods 6, 275-277 (2009).

34. G. M. Shepherd, K. M. Harris, Three-dimensional structure and composition of CA3-->CA1 axons in rat hippocampal slices: implications for presynaptic connectivity and compartmentalization. J Neurosci 18, 8300-8310 (1998).

35. S. tom Dieck, L. Kochen, C. Hanus, M. Heumuller, I. Bartnik, B. Nassim-Assir, K. Merk, T. Mosler, S. Garg, S. Bunse, D. A. Tirrell, E. M. Schuman, Direct visualization of newly synthesized target proteins in situ. Nat Methods 12, 411414 (2015).

36. H. Kang, E. M. Schuman, A requirement for local protein synthesis in neurotrophin-induced hippocampal synaptic plasticity. Science 273, 14021406 (1996).

37. K. M. Huber, J. C. Roder, M. F. Bear, Chemical induction of mGluR5- and protein synthesis--dependent long-term depression in hippocampal area CA1. $J$ Neurophysiol 86, 321-325 (2001).

38. J. Zhong, T. Zhang, L. M. Bloch, Dendritic mRNAs encode diversified functionalities in hippocampal pyramidal neurons. BMC Neurosci 7, 17 (2006).

39. E. S. Lein, M. J. Hawrylycz, N. Ao, M. Ayres, A. Bensinger, A. Bernard, A. F. Boe, M. S. Boguski, K. S. Brockway, E. J. Byrnes, L. Chen, L. Chen, T. M. Chen, M. C. Chin, J. Chong, B. E. Crook, A. Czaplinska, C. N. Dang, S. Datta, N. R. Dee, A. L. Desaki, T. Desta, E. Diep, T. A. Dolbeare, M. J. Donelan, H. W. Dong, J. G. Dougherty, B. J. Duncan, A. J. Ebbert, G. Eichele, L. K. Estin, C. Faber, B. A. Facer, R. Fields, S. R. Fischer, T. P. Fliss, C. Frensley, S. N. Gates, K. J. Glattfelder, K. R. Halverson, M. R. Hart, J. G. Hohmann, M. P. Howell, D. P. Jeung, R. A. Johnson, P. T. Karr, R. Kawal, J. M. Kidney, R. H. Knapik, C. L. Kuan, J. H. Lake, A. R. Laramee, K. D. Larsen, C. Lau, T. A. Lemon, A. J. Liang, Y. Liu, L. T. Luong, J. Michaels, J. J. Morgan, R. J. Morgan, M. T. Mortrud, N. F. Mosqueda, L. L. Ng, R. Ng, G. J. Orta, C. C. Overly, T. H. Pak, S. E. Parry, S. D. Pathak, O. C. Pearson, R. B. Puchalski, Z. L. Riley, H. R. Rockett, S. A. Rowland, J. J. Royall, M. J. Ruiz, N. R. Sarno, K. Schaffnit, N. V. Shapovalova, T. Sivisay, C. R. Slaughterbeck, S. C. Smith, K. A. Smith, B. I. Smith, A. J. Sodt, N. N. Stewart, K. R. Stumpf, S. M. Sunkin, M. Sutram, A. Tam, C. D. Teemer, C. Thaller, C. L. Thompson, L. R. Varnam, A. Visel, R. M. Whitlock, P. E. Wohnoutka, C. K. Wolkey, V. Y. Wong, M. Wood, M. B. Yaylaoglu, R. C. Young, B. L. Youngstrom, X. F. Yuan, B. Zhang, T. A. Zwingman, A. R. Jones, Genome-wide atlas of gene expression in the adult mouse brain. Nature 445, 168-176 (2007).

40. M. M. Poon, S. H. Choi, C. A. Jamieson, D. H. Geschwind, K. C. Martin, Identification of process-localized mRNAs from cultured rodent hippocampal neurons. J Neurosci 26, 13390-13399 (2006).

41. I. J. Cajigas, G. Tushev, T. J. Will, S. tom Dieck, N. Fuerst, E. M. Schuman, The local transcriptome in the synaptic neuropil revealed by deep sequencing and high-resolution imaging. Neuron 74, 453-466 (2012).

42. L. F. Gumy, G. S. Yeo, Y. C. Tung, K. H. Zivraj, D. Willis, G. Coppola, B. Y. Lam, J. L. Twiss, C. E. Holt, J. W. Fawcett, Transcriptome analysis of embryonic and adult sensory axons reveals changes in mRNA repertoire localization. RNA 17, 85-98 (2011). 
43. K. H. Zivraj, Y. C. Tung, M. Piper, L. Gumy, J. W. Fawcett, G. S. Yeo, C. E. Holt, Subcellular profiling reveals distinct and developmentally regulated repertoire of growth cone mRNAs. J Neurosci 30, 15464-15478 (2010).

44. L. A. Autilio, S. H. Appel, P. Pettis, P. L. Gambetti, Biochemical studies of synapses in vitro. I. Protein synthesis. Biochemistry 7, 2615-2622 (1968).

45. I. G. Morgan, L. Austin, Synaptosomal protein synthesis in a cell-free system. J Neurochem 15, 41-51 (1968).

46. S. Maday, A. E. Twelvetrees, A. J. Moughamian, E. L. Holzbaur, Axonal transport: cargo-specific mechanisms of motility and regulation. Neuron $\mathbf{8 4 ,}$ 292-309 (2014).

47. S. J. Tang, G. Reis, H. Kang, A. C. Gingras, N. Sonenberg, E. M. Schuman, A rapamycin-sensitive signaling pathway contributes to long-term synaptic plasticity in the hippocampus. Proc Natl Acad Sci U S A 99, 467-472 (2002).

48. M. A. Sutton, H. T. Ito, P. Cressy, C. Kempf, J. C. Woo, E. M. Schuman, Miniature neurotransmission stabilizes synaptic function via tonic suppression of local dendritic protein synthesis. Cell 125, 785-799 (2006).

49. J. D. Richter, G. J. Bassell, E. Klann, Dysregulation and restoration of translational homeostasis in fragile X syndrome. Nat Rev Neurosci 16, 595605 (2015).

50. M. R. Akins, H. E. Berk-Rauch, K. Y. Kwan, M. E. Mitchell, K. A. Shepard, L. I. Korsak, E. E. Stackpole, J. L. Warner-Schmidt, N. Sestan, H. A. Cameron, J. R. Fallon, Axonal ribosomes and mRNAs associate with fragile $\mathrm{X}$ granules in adult rodent and human brains. Hum Mol Genet 26, 192-209 (2017).

51. K. M. Huber, M. S. Kayser, M. F. Bear, Role for rapid dendritic protein synthesis in hippocampal mGluR-dependent long-term depression. Science 288, 1254-1257 (2000).

52. W. B. Smith, S. R. Starck, R. W. Roberts, E. M. Schuman, Dopaminergic stimulation of local protein synthesis enhances surface expression of GluR1 and synaptic transmission in hippocampal neurons. Neuron 45, 765-779 (2005).

53. G. Tushev, C. Glock, M. Heumuller, A. Biever, M. Jovanovic, E. M. Schuman, Alternative 3' UTRs Modify the Localization, Regulatory Potential, Stability, and Plasticity of mRNAs in Neuronal Compartments. Neuron 98, 495-511 e496 (2018).

54. G. Aakalu, W. B. Smith, N. Nguyen, C. Jiang, E. M. Schuman, Dynamic visualization of local protein synthesis in hippocampal neurons. Neuron $\mathbf{3 0}$, 489-502 (2001).

55. A. S. Hafner, A. C. Penn, D. Grillo-Bosch, N. Retailleau, C. Poujol, A. Philippat, F. Coussen, M. Sainlos, P. Opazo, D. Choquet, Lengthening of the Stargazin Cytoplasmic Tail Increases Synaptic Transmission by Promoting Interaction to Deeper Domains of PSD-95. Neuron 86, 475-489 (2015).

56. C. Fallini, P. G. Donlin-Asp, J. P. Rouanet, G. J. Bassell, W. Rossoll, Deficiency of the Survival of Motor Neuron Protein Impairs mRNA Localization and Local Translation in the Growth Cone of Motor Neurons. J Neurosci 36, 3811-3820 (2016).

57. C. C. Chou, Y. Zhang, M. E. Umoh, S. W. Vaughan, I. Lorenzini, F. Liu, M. Sayegh, P. G. Donlin-Asp, Y. H. Chen, D. M. Duong, N. T. Seyfried, M. A. Powers, T. Kukar, C. M. Hales, M. Gearing, N. J. Cairns, K. B. Boylan, D. W. Dickson, R. Rademakers, Y. J. Zhang, L. Petrucelli, R. Sattler, D. C. Zarnescu, 
J. D. Glass, W. Rossoll, TDP-43 pathology disrupts nuclear pore complexes and nucleocytoplasmic transport in ALS/FTD. Nat Neurosci 21, 228-239 (2018).

58. A. Dobin, C. A. Davis, F. Schlesinger, J. Drenkow, C. Zaleski, S. Jha, P. Batut, M. Chaisson, T. R. Gingeras, STAR: ultrafast universal RNA-seq aligner. Bioinformatics 29, 15-21 (2013).

59. D. J. McCarthy, Y. Chen, G. K. Smyth, Differential expression analysis of multifactor RNA-Seq experiments with respect to biological variation. Nucleic Acids Res 40, 4288-4297 (2012).

60. Y. Benjamini, Y. Hochberg, Controlling the False Discovery Rate: A Practical and Powerful Approach to Multiple Testing. Journal of the Royal Statistical Society. Series B (Methodological) 57, 289-300 (1995).

61. J. C. Oliveros. (2007). An interactive tool for comparing lists with Venn's diagrams.

Venny http://bioinfogp.cnb.csic.es/tools/venny/index.html(2007-2015).

\section{Acknowledgements.}

We thank I. Bartnik, N. Fuerst, A. Staab, D. Vogel and C. Thum for the preparation of cultured neurons, S. tom Dieck and T.W. Lee for important work in preliminary studies, Ha Nguyen for experiments shown in Figure 3J, Maria Florencia Angelo, Anaëlle Stum and Vincent Pitard for technical assistance with FASS experiments (Flow cytometry facility, CNRS UMS 3427, INSERM US 005, Univ. Bordeaux, F33000 Bordeaux, France), Fabrice Cordelières for image analysis routines (Bordeaux Imaging Center, Univ. Bordeaux, F-33000 Bordeaux, France) and Georgi Tushev for help with RNA seq analyses.

Funding: A.S.H. is supported by an EMBO Long-term Postdoctoral Fellowship (ALTF 1095-2015) and the Alexander von Humboldt Foundation (FRA-1184902HFST-P) as well as the National Infrastructure France-Biolmaging supported by the French National Research Agency (ANR-10-INBS-04). P.G.D.A. is supported by the Peter and Traudl Engelhard Stiftung and the Alexander von Humboldt Foundation (USA-1198990-HFST-P). E.M.S. is funded by the Max Planck Society, an Advanced Investigator award from the European Research Council, DFG CRC 1080: Molecular and Cellular Mechanisms of Neural Homeostasis and DFG CRC 902: Molecular Principles of RNA-based Regulation. This project has received funding from the European Research Council (ERC) under the European Union's Horizon 2020 research and innovation program (grant agreement No 743216). B.L. is funded by the Royal Society NZ- Germany Science and Technology Programme FRG-UOO1403. E.H. is funded by the French Agence Nationale de la Recherche (ANR-10-LABX43 BRAIN «Dolipran ») and the Fondation pour la Recherche Médicale (ING20150532192).

Author contributions: A.S.H. and P.D.A. designed, conducted and analyzed experiments. E.H. and B.L. designed and supervised experiments. E.M.S. designed experiments, supervised the project, and wrote the paper. All authors edited the paper.

Competing interests: The authors declare no competing financial interests. 


\section{Figure Legends.}

Fig. 1. Abundant ribosomes and mRNA in presynaptic compartments of the mature mouse forebrain and hippocampus.

(A) Scheme indicating the experimental workflow. Sagittal brain slices from adult mice were processed for FISH and fluorescent immunostaining (IF) for presynaptic terminal types, excitatory (vGLUT1) or inhibitory, (vGAT) and then subjected to a protein retention expansion microscopy protocol (see Methods). For illustration purposes, a brain section is pseudo-colored to indicate the distribution of RNA (lavender) and vGLUT1 (green). (B) Representative images of expanded presynaptic compartments chosen for their positive $\mathrm{VGLUT1}^{+}$or $(\mathbf{C}) \mathrm{VGAT}^{+}$signal (magenta) showing the presence of both small and large ribosomal proteins (green; in first trio of images), large and small ribosomal RNA (green; in middle trio of images) or poly(A) RNA (green; in last trio of images) as well as the merged images showing both signals (last image in each trio). Scale bar = $1.5 \mathrm{um}$. (D) Bar graph showing analysis for all vGLUT1 ${ }^{+}$compartments analyzed from forebrain and the hippocampus. Over $75 \%$ of all vGLUT1+ terminals contained ribosomal proteins and RNA as well as poly (A) RNA. Data acquired from 4 different animals per condition, mean and SEM are plotted. (E) Bar graph showing analysis for all $\mathrm{VGAT}^{+}$ compartments analyzed from forebrain and the hippocampus. Over $75 \%$ of all vGAT terminals contained ribosomal proteins and RNA as well as poly (A) RNA. Data acquired from 4 different animals per condition, mean and SEM are plotted

Fig. 2. Presynaptic compartments isolated from adult mouse brain contain spatially organized mRNA and ribosomes.

(A) Scheme showing experimental flow for analysis of the global (pre-sorted) synaptosome and fluorescently sorted $\mathrm{vGLUT1}^{+}$synaptosome population. (B) Representative electron micrograph of a pre-sorted synaptosome. Scale bar $=200$ nm. (C-D) Example confocal images of sparsely plated vGLUT1 ${ }^{+}$synaptosomes labeled by FISH and immunofluorescence showing the vGLUT1 ${ }^{+}$signal in each synaptosome panel as well as the presence or absence of poly(A) (C) or RPS11 (D) and PSD-95 for the same samples. Merged images are shown in the last panel. 
Scale bar $=5 \mu \mathrm{m}$. (E) Bar graph showing analysis for all synaptosomes analyzed (analysis includes sorted and pre-sorted as both populations yield similar results) ( $\mathrm{n}^{\mathrm{dT}}$ $=921$ and $n^{\mathrm{dA}}=1069$ from 2 biological replicates) showing that $87.6 \%+/-8.4$ of all VGLUT $^{+}$terminals were positive for a FISH oligo-dT probe while less than $17.5 \%+/$ 9.2 were positive for a FISH oligo-dA probe. ${ }^{* *}$ Unpaired t-test, $p \leq 0.01$. (F) Plot of all data points for sorted synaptosomes and median (left) and a scheme (right) showing center-to-center distance between fluorescent signals. The center of the oligo-dT signal (green) was on average $12.8 \mathrm{~nm}$ from the center of the vGLUT1 signal (lavender) and $20.0 \mathrm{~nm}$ from the PSD-95 signal (black). $\left(\mathrm{n}^{\mathrm{vGLUT1}}=317\right.$ and $\mathrm{n}^{\mathrm{PSD}-95}=$ 134) $* * *$ Unpaired t-test, $p \leq 0.001$. (G) Bar graph showing analysis for all synaptosomes analyzed (analysis includes sorted and pre-sorted) ( $n=568$ from 3 biological replicate experiments) showing that $88.9 \%+/-6.9$ of all vGLUT1 ${ }^{+}$ terminals were positive for RPS11 and 63.5\% +/- 14.0 were positive for PSD-95. *** Unpaired t-test, $\mathrm{p} \leq 0.001$. $(\mathbf{H})$ Plot showing the center-to-center distances between fluorescence signals. The center of the RPS11 signal was on average $19.5 \mathrm{~nm}$ from the PSD-95 signal and $15.9 \mathrm{~nm}$ from the center of the vGLUT1 signal. ${ }^{* \star *}$ Unpaired ttest, $p \leq 0.001$. (I) Bar graph showing analysis for all synaptosomes analyzed (forebrain data are the same as in $2 \mathrm{~F}$, for hippocampus and cerebellum we analyzed vGLUT1 ${ }^{+}$sorted synaptosomes) $\left(n^{\text {forebrain }}=568, n^{\text {hippocampus }}=834\right.$ and $n^{\text {cerebellum }}=236$ from at least 2 biological replicate experiments) showing that greater than $80 \%$ of all vGLUT1 $^{+}$terminals were positive for RPS 11 in all 3 brain regions (forebrain $=88.9 \%$ $+/-6.9$; hippocampus $=99.1 \%+/-1.4$; cerebellum $=97.9 \%+/-4.0) .{ }^{\star \star \star}$ KruskalWallis nonparametric test followed by Dunn's multiple comparison test, $p \leq 0.001$. All data are shown as mean $+/-\mathrm{SD}$.

Fig. 3. Ribosomes are spatially offset from the active zone in presynaptic terminals.

(A-C) Synaptosomes were immunostained for vGLUT1 (A), bassoon (B) or RIM1 (C) (magenta) and processed for FISH against 18s rRNA (green). Scale bar = $2.5 \mathrm{um}$. (D-F) Line scan analysis was performed (see methods) to assess the relative spatial distribution of ribosomal RNA in the synaptosomes to the pool of synaptic vesicles or the active zone. Graphs depict the signal distribution of either the presynaptic marker (solid magenta curve) or the ribosomal RNA (solid green curve). Dotted lines indicate 
the peak of the Gaussian fits (black dotted curves), indicating that the ribosomes were offset from the active zone. $n=40$ synaptosomes analyzed from 3 biological replicates. Error bars correspond to SEM. Scale bar $=2.5$ um. (G-I) Representative electron micrographs of pre-sorted synaptosomes after post-embedding immunostaining using an anti-ribosomal protein RPS11 antibody. (G) Electron micrograph showing 3 terminals, 2 of which were associated with a postsynaptic membrane, and 2 of which contained multiple gold particles reflecting the presence of ribosomes in these compartments (solid arrows). Note that there was only 1 gold particle in the field of view outside of terminals (open arrow). Scale bar $=200 \mathrm{~nm}$. (H) Electron micrograph showing a terminal containing multiple gold particles (solid arrows) and an open postsynaptic compartment. Scale bar $=200 \mathrm{~nm}$. (I) Enlarged view of the terminal in the boxed area in $(\mathbf{G})$, suggesting that ribosomes are not present in the active zone. Scale bar $=200 \mathrm{~nm}$. (J) Bar graph showing RPS11 occupancy in synapses from immunoEM images $(82.7+/-4.7, \mathrm{n}=2$ biological replicates and 147 terminal counted). Data are shown as mean +/- SD.

\section{Fig. 4. An excitatory presynaptic transcriptome from mature mouse synapses.}

(A) Differential expression analysis (see Methods) showing the relationship between expression (reads per million) and the significant enrichment (green dots) or depletion (magenta dots) in the vGLUT1 ${ }^{+}$sorted vs. pre-sorted synaptosomes. (B) Selected list of significantly enriched individual vGLUT1 ${ }^{+}$presynaptic transcripts. (C) Selected Gene Ontology (GO) annotations of transcripts significantly enriched by vGLUT1 $^{+}$sorting. (D) Selected Gene Ontology (GO) annotations of transcripts significantly depleted by $\mathrm{vGLUT1}^{+}$sorting. (E) Comparison of the percentage of mRNA containing FMR1 sites binding in the forebrain transcriptome (input) or contaminant transcriptome (depleted) or VGLUT1 ${ }^{+}$-enriched presynaptic transcriptome (enriched). (F) Schematic representation of a vGLUT1 ${ }^{+}$presynaptic terminal with the localization of a subset of proteins coded by mRNA detected using Next Generation RNA sequencing of synaptosomes. Note that many presynaptic active zone-related mRNAs are enriched by the sorting procedure (green) whereas synaptic vesicle-related mRNAs are either significantly depleted (magenta) or not enriched by sorting. (G) FISH conducted on isolated vGLUT1 $^{+}$synaptosomes 
validating the presence of Rapgef4, Adcy1, Bsn, Kif5 and the absence of Actb mRNA in vGLUT1 ${ }^{+}$terminals. (H). Bar graph showing the analysis of $\mathrm{FISH}$ data indicating the percentage of $\mathrm{VGLUT}^{+}$synaptosomes that possess the indicated mRNA $\left(\mathrm{n}^{\text {Rapgef4 }}\right.$ $=939, \mathrm{n}^{\text {Adcy } 1}=551, \mathrm{n}^{\text {Bsn }}=1437, \mathrm{n}^{\text {Kif5 }}=1292$ and $\mathrm{n}^{\text {Actb }}=359$ vGLUT1 ${ }^{+}$terminals from at least 2 biological replicate experiments). Data are shown as mean +/- SD (Rapgef4 $=55.6 \%+/-12.6$; Adcy1 = 56.5\% +/- 12.3; Bsn = 41.3\% +/- 10.4; Kif5a $=38.4 \%+/-$ 14.7; Actb $=4.0 \%+/-6.0) . \quad$ * Kruskal-Wallis nonparametric test followed by Dunn's multiple comparison test, $\mathrm{p} \leq 0.05$. All scale bars $=5 \mu \mathrm{m}$.

Fig. 5. In vivo isolated pre- and postsynaptic compartments actively translate protein in the absence of external stimulation.

(A) Electron microscope (EM) images of cultured hippocampal neurons metabolically labeled with puromycin for $10 \mathrm{~min}$ and then detected using immunogold (see Methods). Electron-dense particles indicate sites of protein synthesis. Shown are dendritic segments (left) and synapses (right) with gold particles present throughout the dendrite as well as in both the presynaptic (shaded lavender) and postsynaptic (shaded pale green) compartments in the absence of anisomycin. Yellow arrows indicate protein synthesis sites in presynaptic boutons. Scale bars $=1$ and $0.2 \mu \mathrm{m}$, for dendrite and synapse, respectively. (B-C) Plots indicating the number of nascent protein immunogold labeling and the corresponding median in dendritic spines $\left(\mathrm{n}^{+ \text {puro }}\right.$ $\left.=49, \mathrm{n}^{\text {+aniso }}=21, \mathrm{n}^{\text {-puro }}=14\right)(\mathrm{B})$ and presynaptic boutons $\left(\mathrm{n}^{+ \text {puro }}=54, \mathrm{n}^{\text {+aniso }}=11, \mathrm{n}^{-}\right.$ puro $=13)(\mathbf{C})$ in presence of puromycin (10 min incubation) with or without the translation inhibitor anisomycin (40 min incubation in total) and in the absence of puromycin (spines: +puro $=5$, aniso $=2$, -puro $=0$; boutons: + puro $=1$, aniso $=0$, puro $=0$ ). Quantifications were obtained from 2 biological replicates. ${ }^{*}$ Kruskal-Wallis nonparametric test followed by Dunn's multiple comparison test, $p \leq 0.05$. (D) Representative images of expanded cultured hippocampal neurons following 5 min of metabolic labeling and immunolabeling showing nascent protein detected in dendritic spines, excitatory presynaptic boutons or inhibitory presynaptic boutons. (E) Quantifications of metabolic labeling showing that a large fraction of both pre- and postsynaptic compartments were translationally active within $5 \mathrm{~min}$ of metabolic labeling. Data are shown as mean +/- SD (spine $=64.2+/-8.8$, vGAT $=44.4+/-9.7$, vGLUT1 $=33.5+/-12.0) .{ }^{* * * K r u s k a l-W a l l i s ~ n o n p a r a m e t r i c ~ t e s t ~ f o l l o w e d ~ b y ~ D u n n ' s ~}$ 
multiple comparison test, $p \leq 0.001$. (F) Quantification of puromycin occupancy revealed that the inhibition of mitochondrial protein synthesis had no effect in vGLUT1+ puncta. Data are shown as mean +/- SD (baseline = 37.3 +/- 15.9, chloramphenicol $=33.7+/-15.0$, anisomycin $=7.6+/-5.8) . n=3$ biological replicates, 300 vGLUT1+ terminals quantified. Dunnett's multiple comparison test, $p$ value: * $\leq$ 0.05. (F-G) Representative images showing newly synthesized proteins-of-interest, RapGEF4 and Bassoon, which were also identified as transcripts enriched in the vGLUT1+ transcriptome (Fig. 4B,F,G). Scale bars $=20$ and $5 \mu \mathrm{m}$, for $(\mathbf{G})$ and $(\mathbf{D})(\mathbf{H})$ respectively.

Fig. 6. Compartment-specific translation patterns decode different forms of plasticity.

(A) Scheme showing the timing of the different plasticity induction protocols and the metabolic labeling (+puro). (B) Representative images from hippocampal cultures showing both the immunostained, and metabolically labelled compartments indicating newly synthesized protein following expansion microscopy for one of the plasticity conditions (+/- BDNF). Scale bar $=5 \mu \mathrm{m}$. (C) Bar graphs indicating the specific translation pattern in different subcellular compartments $\left(\mathrm{VGAT}^{+}\right.$or $\mathrm{vGLUT1}^{+}$ presynaptic terminals or spine) following the 3 different plasticity treatments, normalized to the control condition in hippocampal cultures, $n=4-6$ biological replicates per condition, for total puncta counted see numbers in the matrix shown in D. Unpaired t-tests, $p$ values: ${ }^{* *} \leq 0.01,{ }^{* * *} p \leq 0.0001$. (D) Matrices for hippocampal and cortical neurons showing both the synaptic compartment (spine, excitatory presynaptic compartment or inhibitory presynaptic compartment) and the plasticity agonist (BDNF, DHPG or ACEA) applied and the percentage of compartments that exhibited protein synthesis. Shown in parentheses are the numbers of labeled compartments over the total number of compartments examined. Colors represent the change in protein synthesis- with green and lavender colors indicating a stimulation or repression of protein synthesis, respectively (see color look-up table). (E) Summary scheme indicating how each different form of plasticity examined has a specific translational signature. The 3 compartments represented by the horizontal boxes indicate the stimulation of protein synthesis by DHPG, BDNF, or ACEA, in that order. 
Figure 1

A

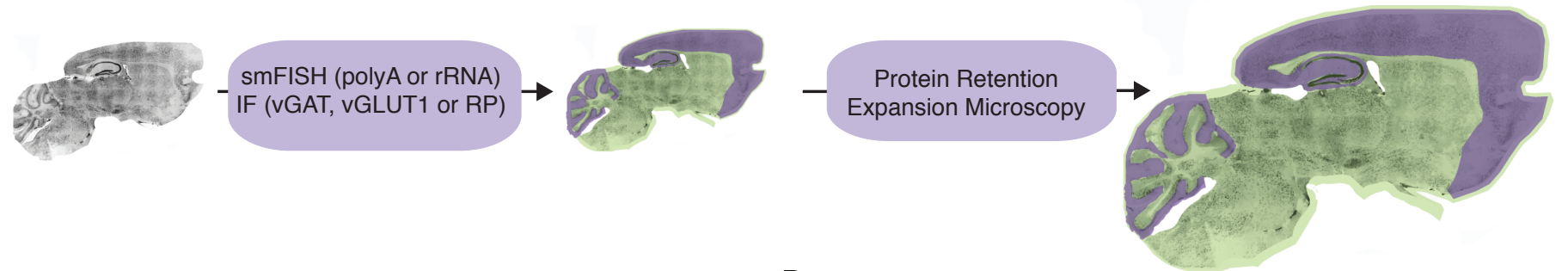

B
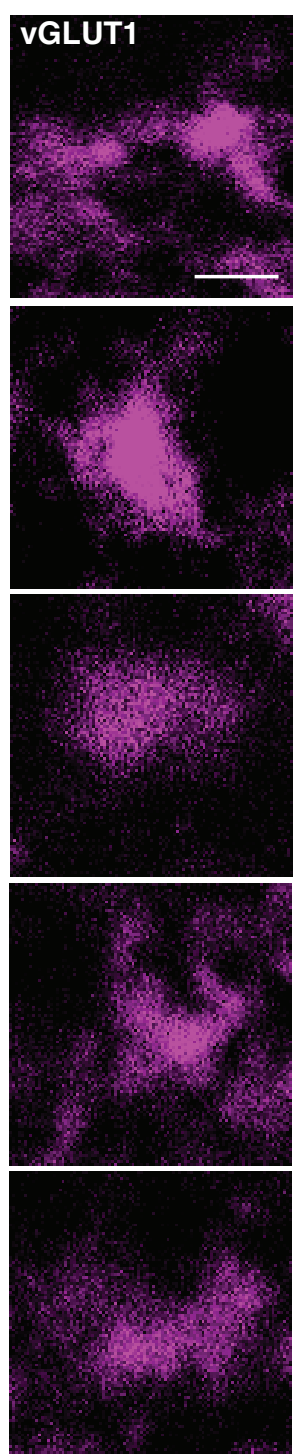

C

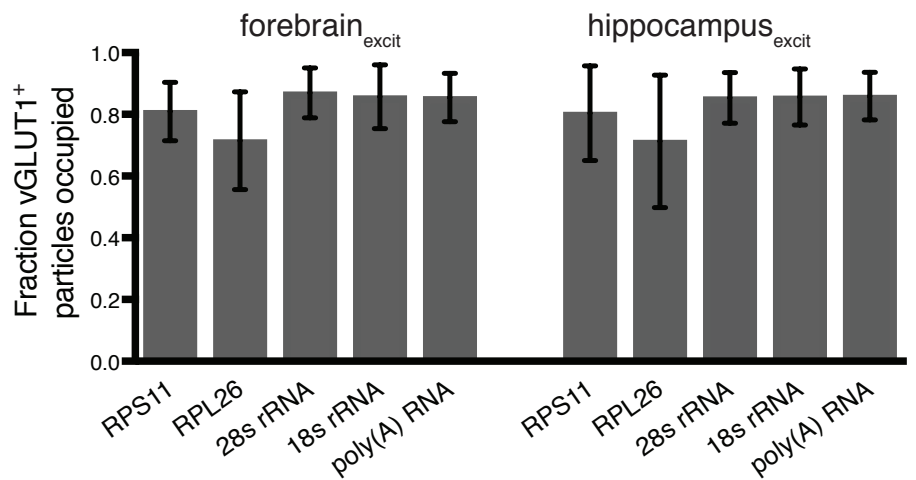

28S rRNA

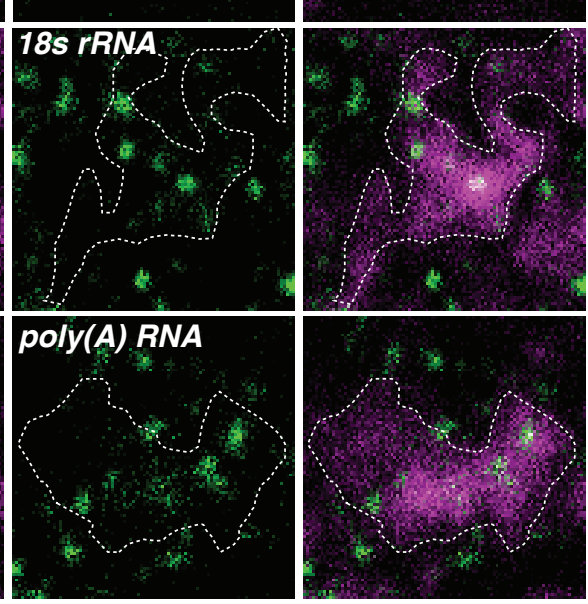

D
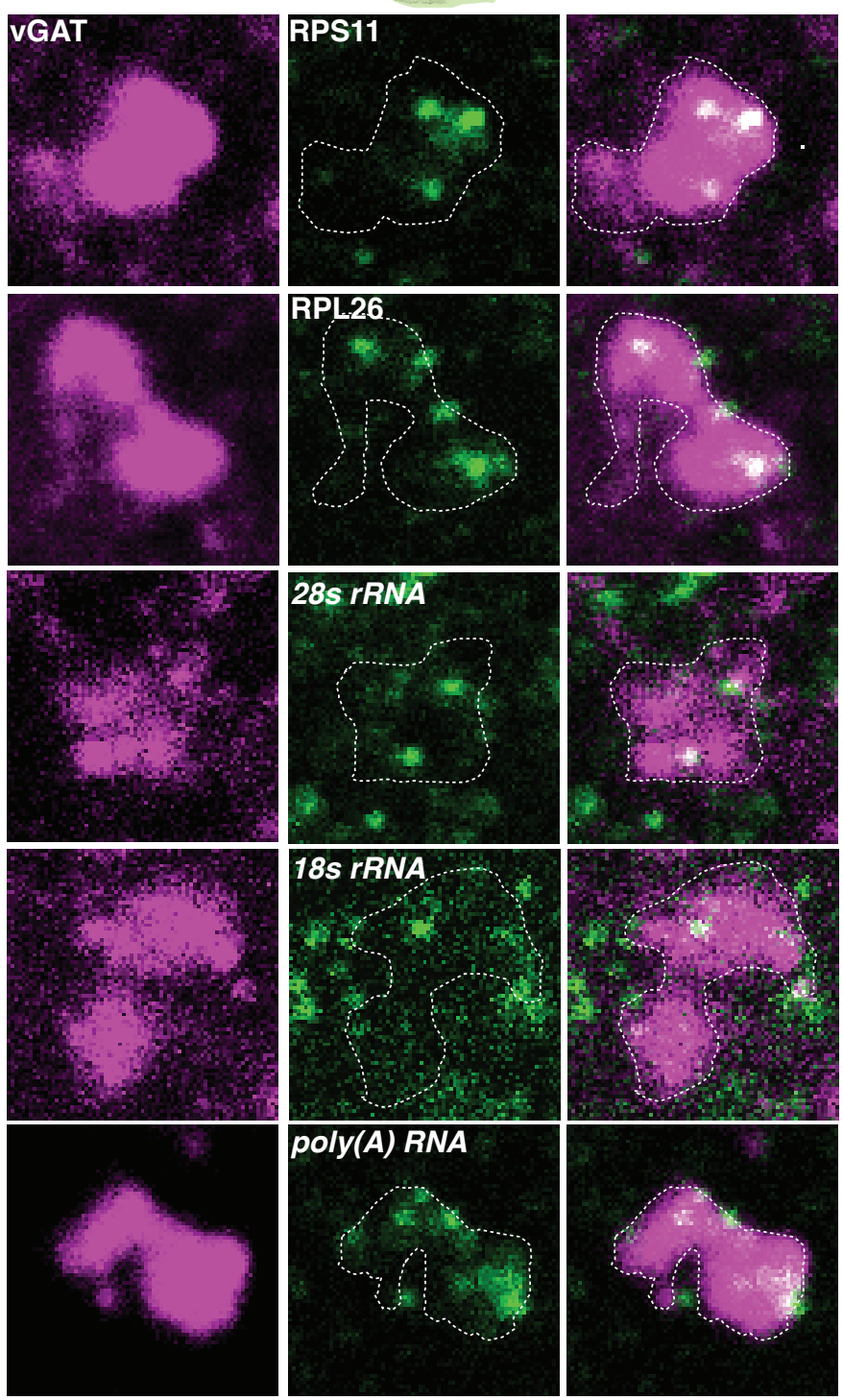

28s rRNA

E

forebrain $_{\text {inhib }}$

hippocampus $_{\text {inhib }}$

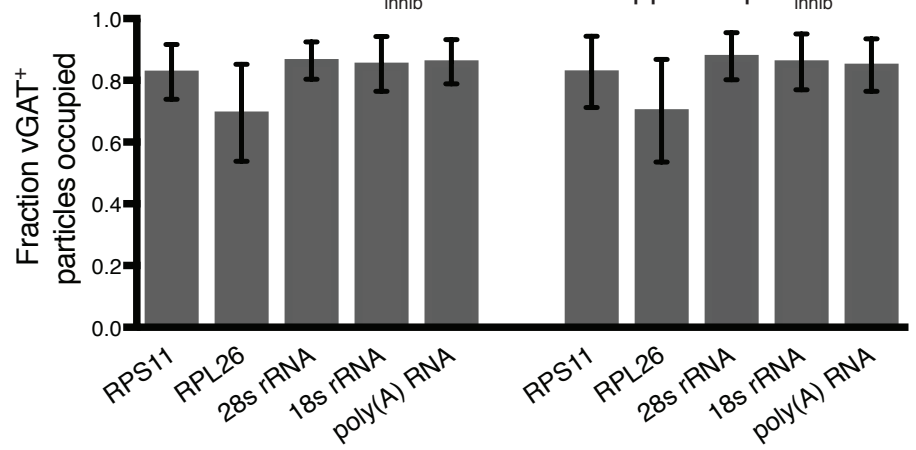




\section{Figure 2}

A

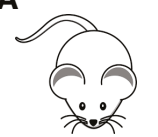

forebrain
dissection $\rightarrow \begin{gathered}\text { subcellular } \\ \text { fractionation }\end{gathered} \rightarrow \begin{gathered}\text { pre-sorted } \\ \text { synaptosomes }\end{gathered}$

Fluorescence Activated

Synaptosome Sorting

vGLUT1 VENUS hippocampus

or

wildtype

dissection
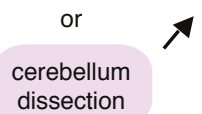

dissection

Next Generation

RNA sequencing

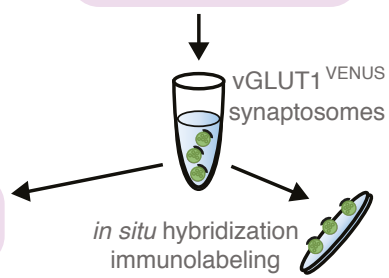

B

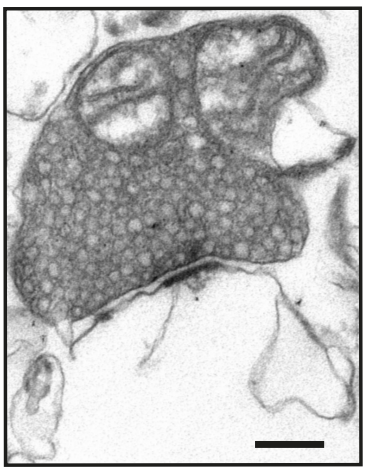

C
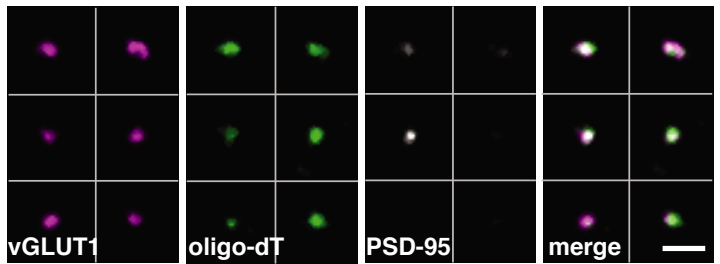

D
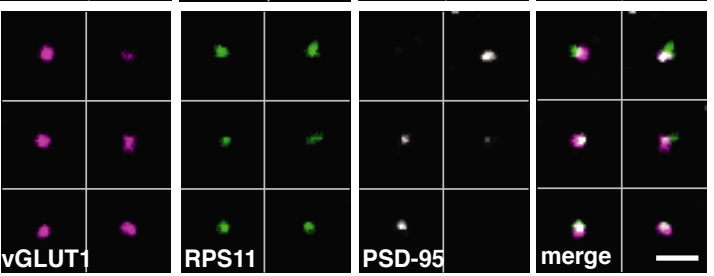

E

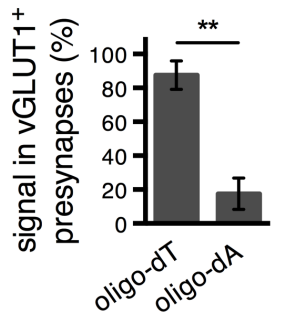

$\mathbf{F}$

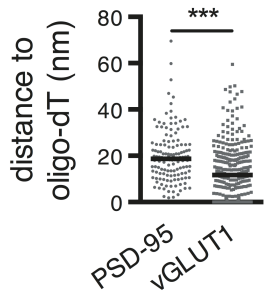

H
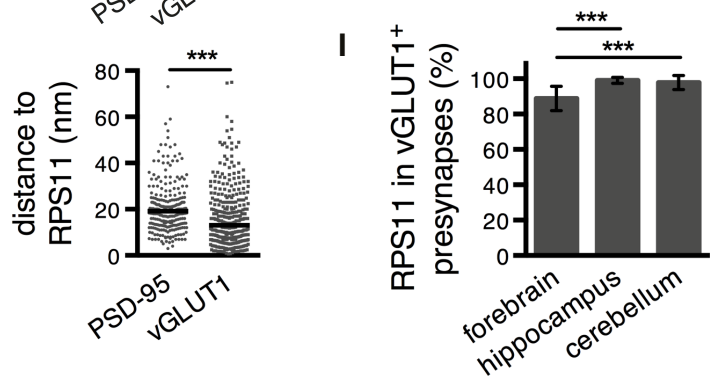
Figure 3
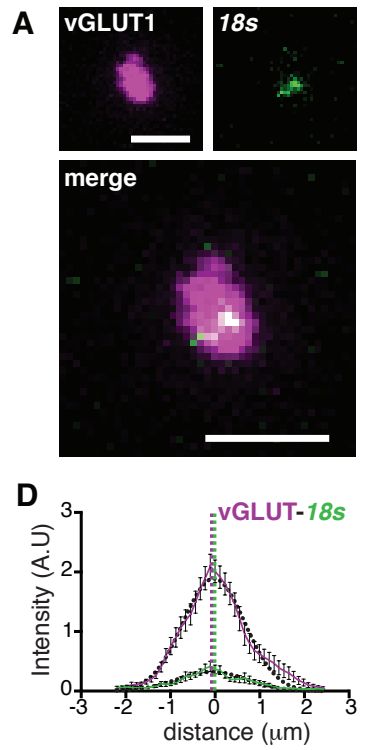

G
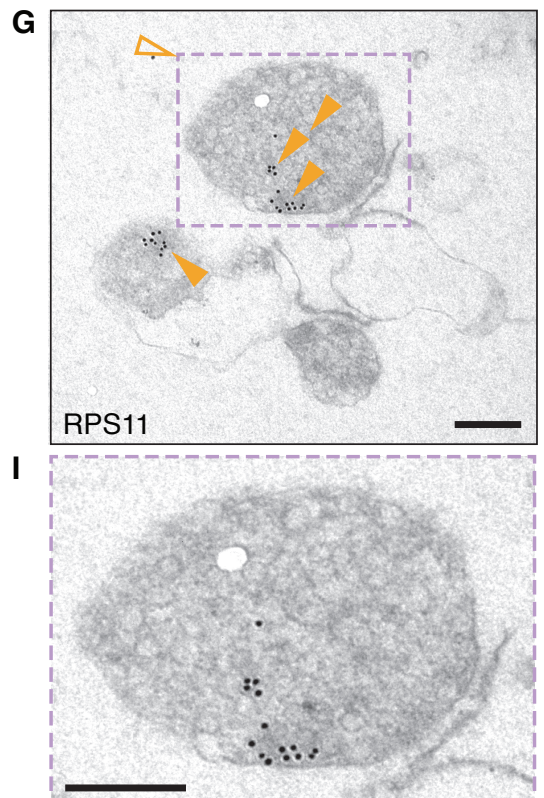
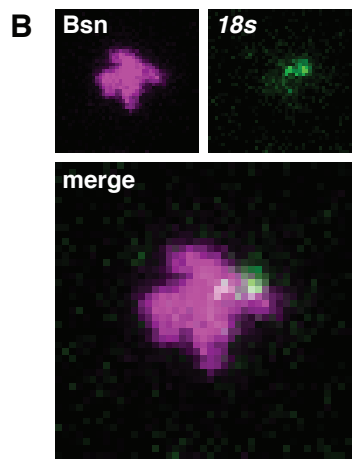

E
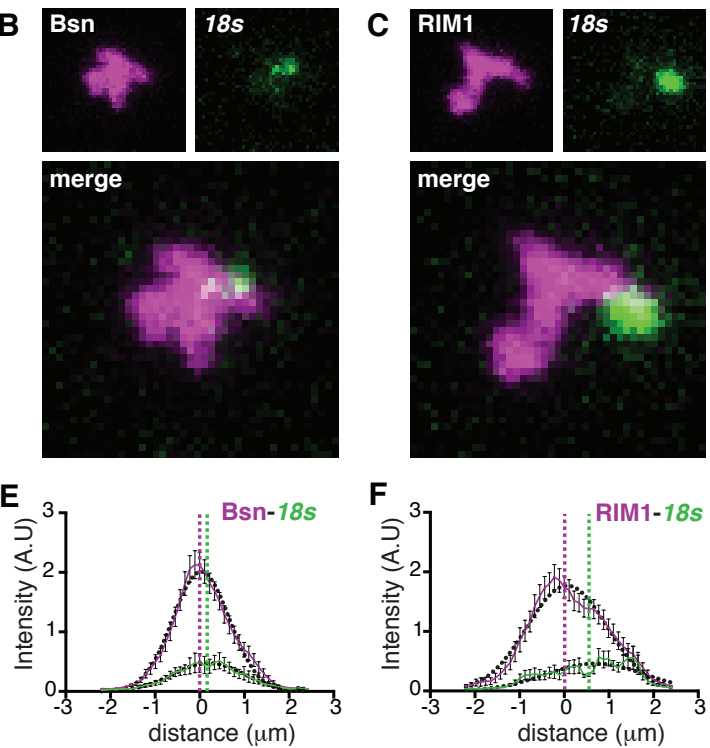

H

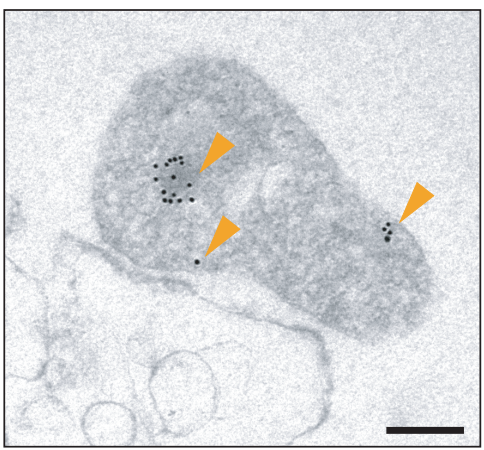

J

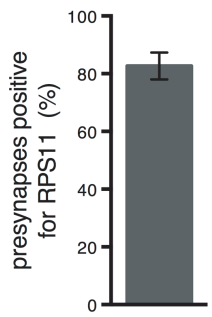


A pre-sorted vs vGLUT1+ sorted synaptosomes ${ }^{\mathrm{NS}}$ synaptosomes

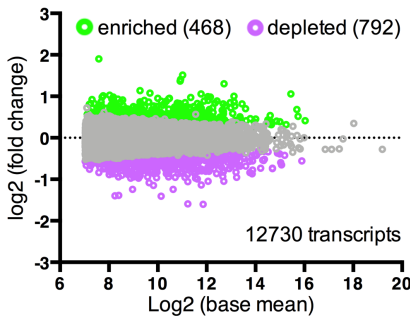

D

endoplasmic reticulum ${ }^{\star}$ (1) GABA receptor complex* (2) signal peptidase complex (3) proton-transporting V-type ATPase* (4) oligosaccharyltransferase complex (7) AMPA receptor complex* (8) chloride channel complex (12) postsynaptic membrane* ${ }^{*}(15)$ dendritic membrane (14) synaptic vesicle membrane ${ }^{*}(16)$ neuron to neuron synapse (25) lysosome (59) axon (76) Golgi apparatus (106)

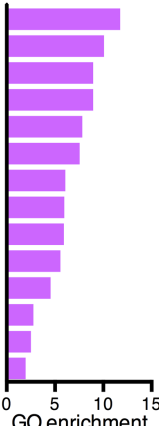

E

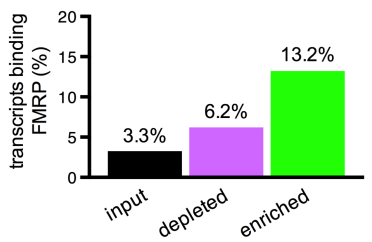

G
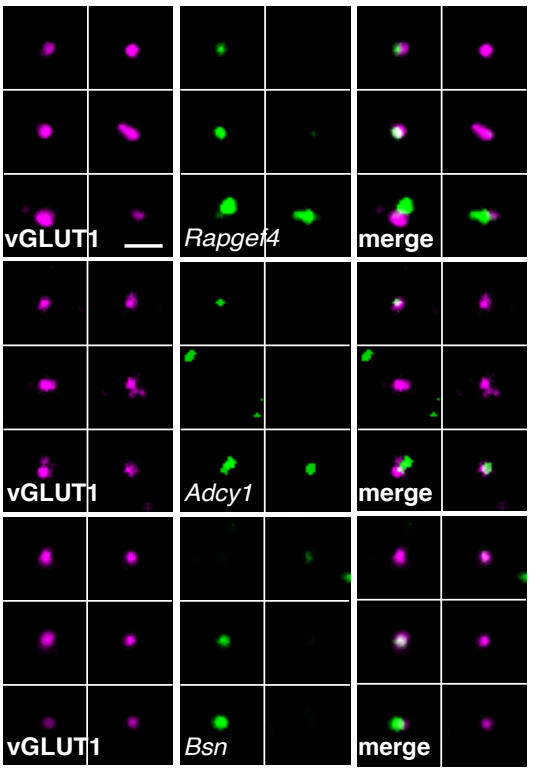

B

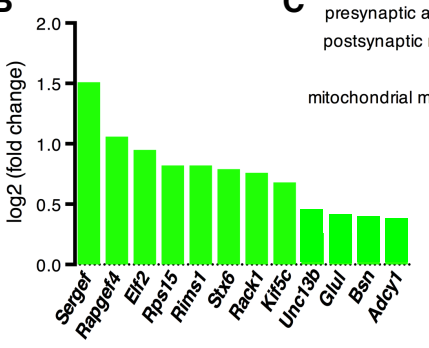

$\mathbf{F}$ presynaptic terminal

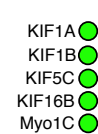

Spectrin $\beta \bigcirc$

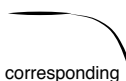
transcripts are:

$O$ enriched

Odepleted

\section{transport}

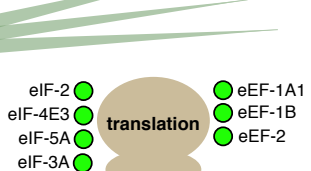
elF-3AO HLC-7O

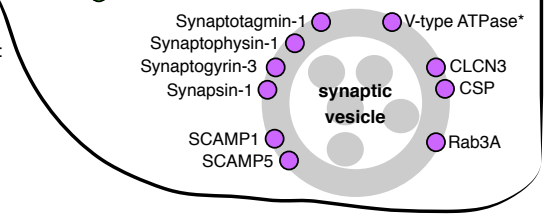

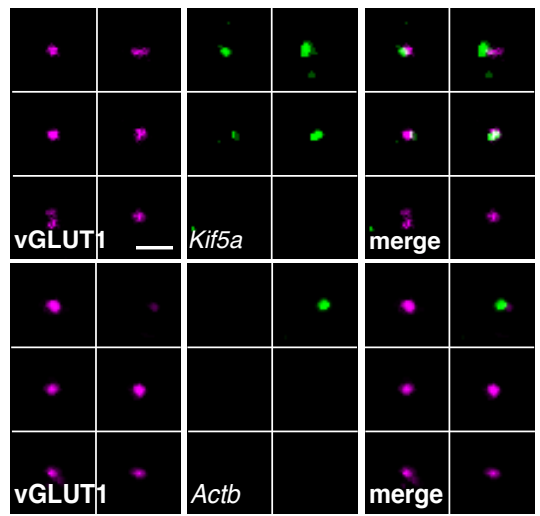

H

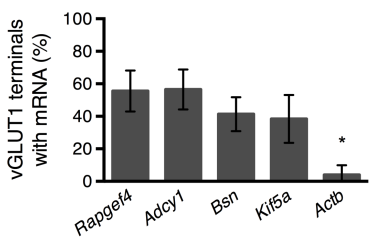




\section{Figure 5}

A
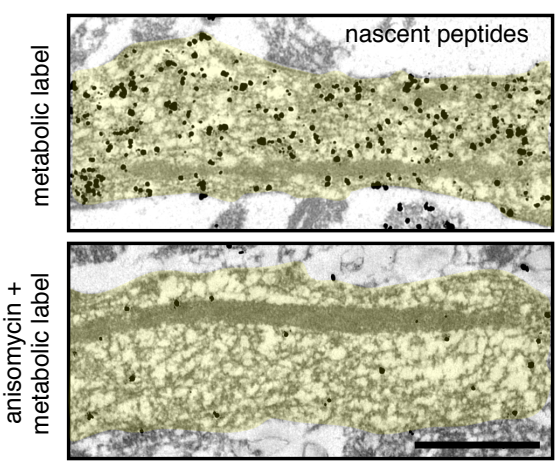

D

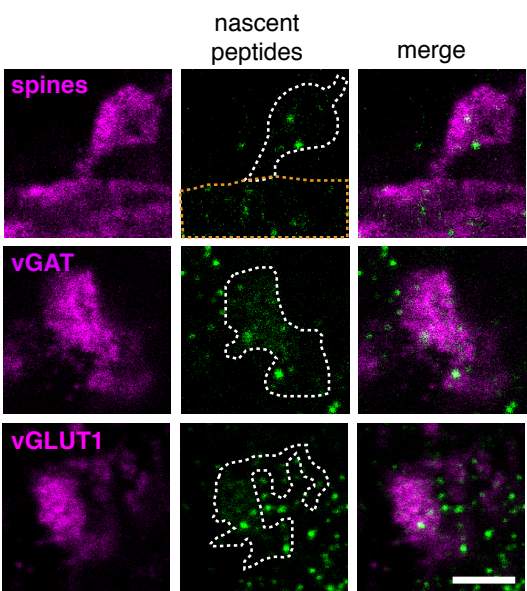

E

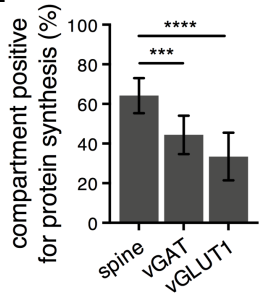

$F \stackrel{0}{2}$

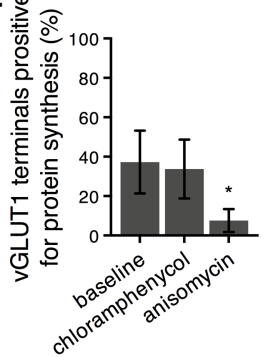

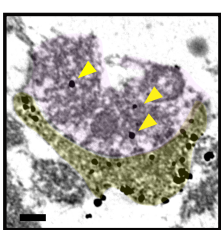

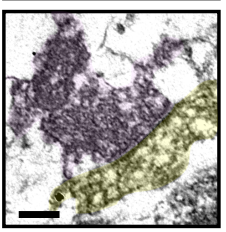

G
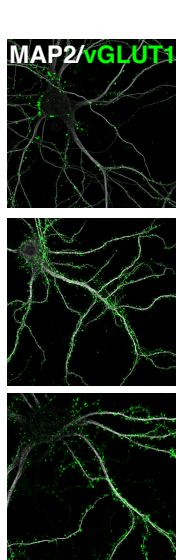

H

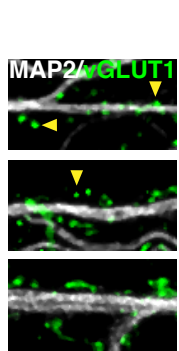

B

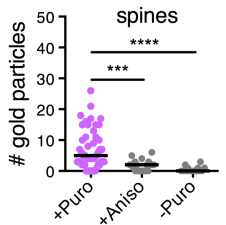

C

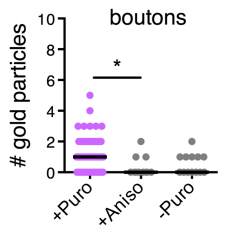

nascent

peptides
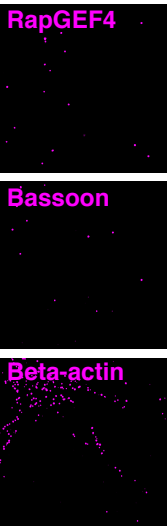

nascent

peptides
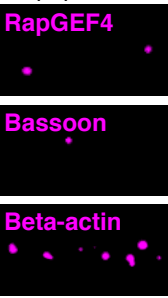

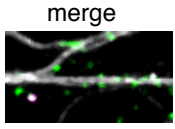

merge
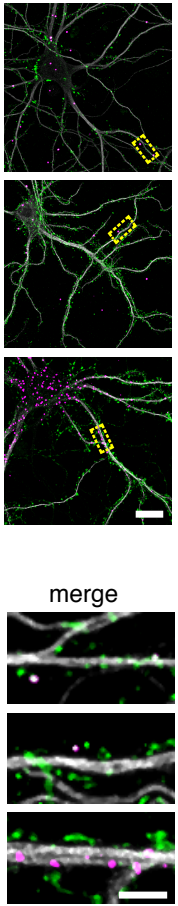


\section{Figure 6}

A

\section{C}

+/-Aniso

B

$\begin{array}{cc}\text { or } & \\ + \text { +- ACEA } & +/ \text { - DHPG } \\ & + \text { Puro }\end{array}$

Control +BDNF

Spines
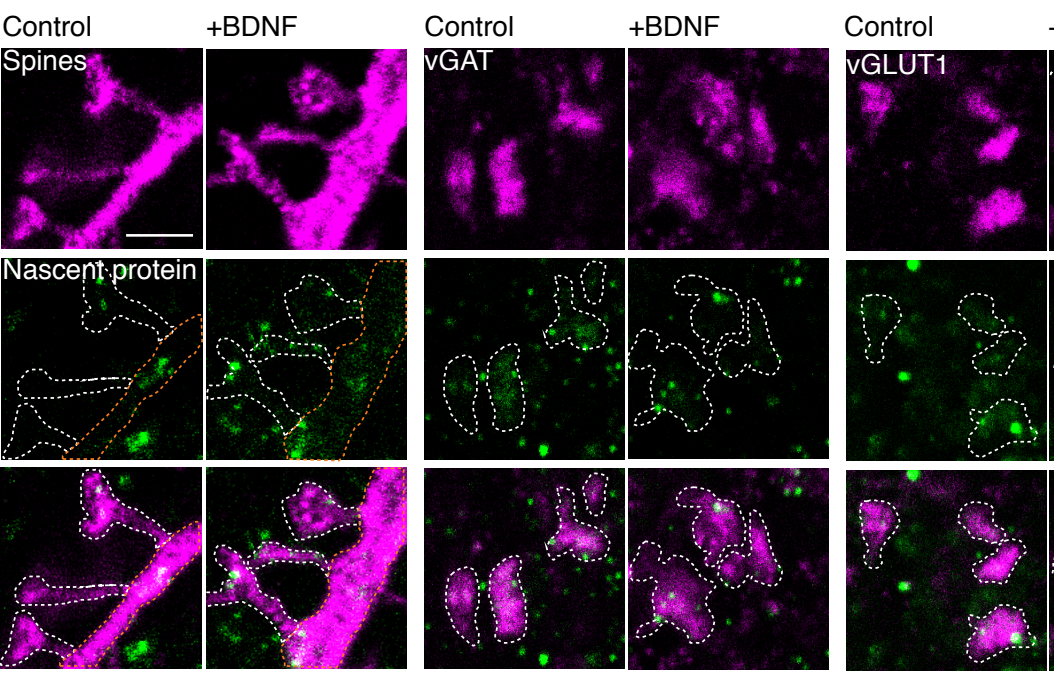

+BDNF

D

Hippocampal neurons

Cortical neurons

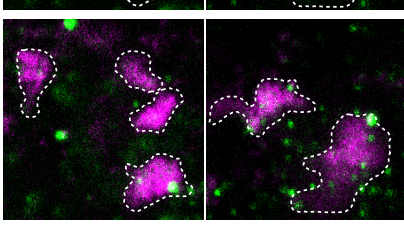

E
BDNF

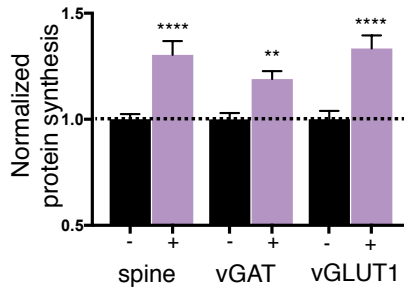

DHPG
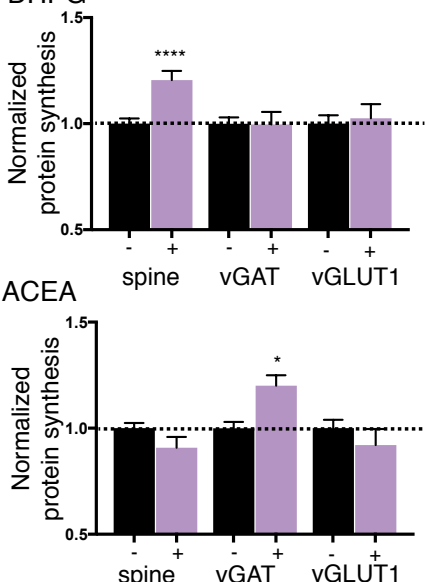

\begin{tabular}{|c|c|c|c|}
\hline & spines & vGAT & vGLUT1 \\
\hline $\begin{array}{l}\overline{0} \\
\text { 흔 }\end{array}$ & $\begin{array}{r}60.8 \% \\
(1852 / 3045)\end{array}$ & $\begin{array}{r}44.2 \% \\
(1693 / 3830)\end{array}$ & $\begin{array}{r}36.6 \% \\
(1208 / 3302)\end{array}$ \\
\hline 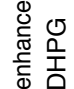 & $\begin{array}{l}74.4 \% \\
(915 / 1231)\end{array}$ & $\begin{array}{l}44.3 \% \\
(630 / 1421)\end{array}$ & $\begin{array}{l}37.1 \% \\
(417 / 1123)\end{array}$ \\
\hline 岂 & $\begin{array}{r}80.4 \% \\
(1208 / 1502)\end{array}$ & $\begin{array}{l}52.9 \% \\
(742 / 1402)\end{array}$ & $\begin{array}{l}48.3 \% \\
(583 / 1206)\end{array}$ \\
\hline 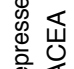 & $\begin{array}{l}49.8 \% \\
(602 / 1210)\end{array}$ & $\begin{array}{l}53.5 \% \\
(664 / 1242)\end{array}$ & $\begin{array}{l}33.3 \% \\
(391 / 1173)\end{array}$ \\
\hline$\frac{0}{\frac{.0}{E}}$ & $\begin{array}{l}14.3 \% \\
(413 / 2892)\end{array}$ & $\begin{array}{l}13.9 \% \\
(528 / 3797)\end{array}$ & $\begin{array}{l}13.3 \% \\
(392 / 2940)\end{array}$ \\
\hline
\end{tabular}

\begin{tabular}{|c|c|c|}
\hline spines & vGAT & vGLUT1 \\
\hline $\begin{array}{r}57.6 \% \\
(548 / 951)\end{array}$ & $\begin{array}{r}42.7 \% \\
(400 / 936)\end{array}$ & $\begin{array}{r}34.2 \% \\
(311 / 909)\end{array}$ \\
\hline $\begin{array}{r}65.1 \% \\
(550 / 845)\end{array}$ & $\begin{array}{r}38.3 \% \\
(303 / 792)\end{array}$ & $\begin{array}{r}33.8 \% \\
(298 / 881)\end{array}$ \\
\hline $\begin{array}{r}70.3 \% \\
(536 / 762)\end{array}$ & $\begin{array}{r}55.2 \% \\
(447 / 810)\end{array}$ & $\begin{array}{r}47.4 \% \\
(398 / 840)\end{array}$ \\
\hline $\begin{array}{r}52.0 \% \\
(427 / 821)\end{array}$ & $\begin{array}{r}54.4 \% \\
(401 / 738)\end{array}$ & $\begin{array}{r}33.8 \% \\
(288 / 852)\end{array}$ \\
\hline $\begin{array}{r}15.2 \% \\
(112 / 440)\end{array}$ & $\begin{array}{r}14.6 \% \\
(125 / 855)\end{array}$ & $\begin{array}{r}16.4 \% \\
(143 / 873)\end{array}$ \\
\hline
\end{tabular}

vGLUT1 presynapse

mRNAs encoding

for 468 synaptic proteins

80

0000000000000


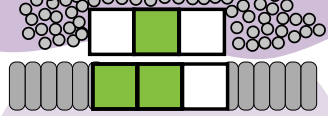

80

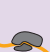

vGAT presynapse

postsynapse
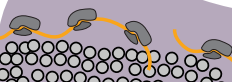

8888880003000

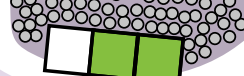

